\title{
Characterization of Subjective Uncertainty in the 1996 Performance Assessment for the Waste Isolation Pilot Plant
}

\author{
J.C. Helton ${ }^{a}$, M.-A. Martell ${ }^{b}$ and M.S. Tierney \\ aDepartment of Mathematics, Arizona State University, Tempe, AZ 85287 USA; bSandia National \\ Laboratories, Albuquerque, NM 87185 USA
}

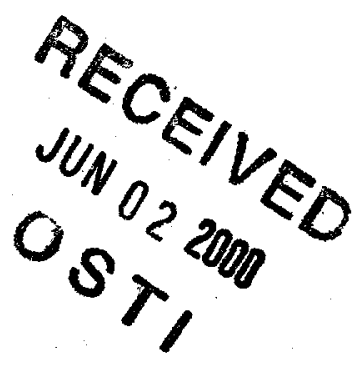

\begin{abstract}
The 1996 performance assessment (PA) for the Waste Isolation Pilot Plant (WIPP) maintains a separation between stochastic (i.e., aleatory) and subjective (i.e., epistemic) uncertainty, with stochastic uncertainty arising from the possible disruptions that could occur at the WIPP over the $10,000 \mathrm{yr}$ regulatory period specified by the U.S. Environmental Protection Agency (40 CFR 191, 40 CFR 194) and subjective uncertainty arising from an inability to uniquely characterize many of the inputs required in the 1996 WIPP PA. The characterization of subjective uncertainty is discussed, including assignment of distributions, uncertain variables selected for inclusion in analysis, correlation control, sample size, statistical confidence on mean complementary cumulative distribution functions, generation of Latin hypercube samples, sensitivity analysis techniques, and scenarios involving stochastic and subjective uncertainty.
\end{abstract}

Key Words: Aleatory uncertainty, complementary cumulative distribution function, compliance certification application, epistemic uncertainty, Latin hypercube sampling, performance assessment, radioactive waste, scenario, stochastic uncertainty, subjective uncertainty, transuranic waste, Waste Isolation Pilot Plant, 40 CFR 191, 40 CFR 194.

Please send page proof to:

Jon C. Helton

Department 6848, MS 0779

Sandia National Laboratories

Albuquerque, NM 87185-0779, USA

Phone: $505-284-4808$

Fax: 505-844-2348

email: jchelto@sandia.gov 


\section{DISCLAIMER}

This report was prepared as an account of work sponsored by an agency of the United States Government. Neither the United States Government nor any agency thereof, nor any of their employees, make any warranty, express or implied, or assumes any legal liability or responsibility for the accuracy, completeness, or usefulness of any information, apparatus, product, or process disciosed, or represents that its use would not infringe privately owned rights. Reference herein to any specific commercial product, process, or service by trade name, trademark, manufacturer, or otherwise does not necessarily constitute or imply its endorsement, recommendation, or favoring by the United States Government or any agency thereof. The views and opinions of authors expressed herein do not necessarily state or reflect those of the United States Government or any agency thereof. 


\section{DISCLAIMER}

Portions of this document may be illegible in electronic image products. Images are produced from the best available original document. 


\section{Introduction}

At a conceptual level, the 1996 performance assessment (PA) for the Waste Isolation Pilot Plant (WIPP) is underlain by three entities (EN1, EN2, EN3): EN1, a probabilistic characterization of the likelihood of different futures occurring at the WIPP site over the next 10,000 yr (Sect. 3, Ref. 1); EN2, a procedure for estimating the radionuclide releases to the accessible environment associated with each of the possible futures that could occur at the WIPP site over the next 10,000 yr (Sect. 4, Ref. 1); and EN3, a probabilistic characterization of the uncertainty in the parameters used in the definition of EN1 and EN2 (Sect. 5, Ref. 1). The third entity, EN3, and its role in the 1996 WIPP PA is the primary focus of this article.

When viewed formally, EN3 is defined by a probability space $\left(\mathrm{S}_{s u}, \&_{s u}, p_{s u}\right)$ for subjective uncertainty (Sect. 5, Ref. 1). Further, the elements $x_{s u}$ of the sample space $S_{s u}$ are vectors of the form

$$
\mathbf{x}_{s u}=\left[x_{1}, x_{2}, \ldots, x_{n}\right] \text {, }
$$

where each $x_{j}$ is an imprecisely known input to the analysis and $n V$ is the number of such inputs.

The uncertainty in the $x_{j}$, and hence in $x_{s u}$, is characterized by developing a distribution

$$
D_{j}, j=1,2, \ldots, n V \text {, }
$$

for each $x_{j}$. Each distribution is based on all available knowledge about the corresponding variable and describes a degree of belief as to where the appropriate value to use for this variable is located. This degree of belief is conditional on the numerical, spatial and temporal resolution of the models selected for use in the 1996 WIPP PA (Sect. 4, Ref. 1; Refs. 2 - 6). When appropriate, correlations between imprecisely-known variables are also possible, with such correlations indicating a dependency in the knowledge about the correlated variables. It is the distributions in Eq. (2) and any associated correlations between the $x_{j}$ that define $\left(\mathrm{S}_{s u}, \& \quad s u, p_{s u}\right)$.

The characterization of the (subjective) uncertainty in variables used as input to the 1996 WIPP PA derives from experimental programs carried out in support of the development of the WIPP and also from other sources of information. The experimental programs that helped characterize input to the 1996 WIPP PA are reviewed in Ref. 7, and the procedures used to develop characterizations of subjective uncertainty are discussed in Sect. 2. Then, the uncertain variables incorporated into the 1996 WIPP PA and the distributions and correlations assigned to these variables are described in Sects. 3 - 5. Further, the archival storage and retrieval of data is discussed in Refs. 8 and 9.

Latin hypercube sampling ${ }^{10}$ is used to propagate the effects of subjective uncertainty in the 1996 WIPP PA (Sect. 5, Ref. 1; Sect. 9, Ref. 11). Technical aspects of the generation of Latin hypercube samples (LHSs) in the 
1996 WIPP PA are discussed in Sects. $6-8$, including sample size (Sect. 6), statistical confidence on mean complementary cumulative distribution functions (CCDFs) (Sect. 7), and generation of replicated LHSs (Sect. 8).

An important aspect of the use of Latin hypercube sampling to propagate the effects of subjective uncertainty in the 1996 WIPP PA is that this propagation generates a mapping from uncertain analysis inputs to corresponding analysis results. This mapping can then be explored with sensitivity analysis techniques based on examination of scatterplots, regression analysis and correlation analysis to determine the dominant variables influencing the uncertainty in the model predictions underlying the analysis (Sect. 9). All major analysis results generated in the 1996 WIPP PA are examined with the indicated sensitivity analysis procedures. ${ }^{3-6,12-14}$

Scenarios are an important conceptual part of the representation of stochastic uncertainty and correspond to subsets of the associated sample space $S_{s t}$ (Sect. 14, Ref. 11). An important extension of the scenario concept is to scenarios that are subsets of the sample space $S_{s u}$ associated with subjective uncertainty and, more generally, to scenarios that derive from the sample spaces för both stochastic and subjective uncertainty (Sect. 10). A concluding discussion on the treatment of subjective uncertainty in the 1996 WIPP is given in Sect. 11.

This article is based on material contained in Chapt. 5 of Ref. 15.

\section{Assignment of Distributions}

The word "parameter" here means a number that must be supplied to a computer model of a system in order that the model's associated computer program will run. Elsewhere in this presentation, parameters are often called "input variables" or simply "variables." We will nevertheless use "parameter" throughout this section to be consistent with earlier documents relating to subjective uncertainty in the 1996 WIPP PA (e.g., App. PAR, Ref. 16.)

The computational models used in the 1996 WIPP PA required more than 1500 parameters, which can be divided into two categories: (i) program configuration parameters, the numbers used to control rate-of-convergence and accuracy of numerical solutions of the model equations (e.g., time-step limits, convergence criteria, array dimensions, ...), and (ii) model configuration parameters, which are numbers that specify geometrical or physical properties of features, events and processes being modeled (e.g., areas of mined openings, rock permeabilities, rates of mining and drilling in vicinity of site, ...). Program configuration parameters, the "knobs" of a computer program, ideally are assigned values by persons who perform a computation with the intent of reducing run times, numerical errors, or memory requirements. Model configuration parameters, on the other hand, ideally are assigned values based on empirical evidence associated with the system being modeled; such evidence may exist in the form of design drawings, results of site specific field and laboratory experiments (or experiments with system analogues), scientific literature, or the specialized knowledge of experts. Because of absent, insufficient or equivocal empirical information, many model configuration parameters are imprecisely known; that is, there is uncertainty concerning the 
values they should take in the context of the problem under consideration. This kind of uncertainty can be quantitatively expressed by constructing probability distributions for the values to be taken on by the imprecisely known parameters. Such distributions characterize subjective uncertainty.

The 1470 model configuration parameters in the 1996 WIPP PA calculations were divided into four categories on the basis of the kinds of information that were used to assign parameter values. Category 1 parameters (409 of them) were assigned values (or distribution of values) using data from site-specific field or laboratory experiments. Category 2 parameters ( 89 of them) represented the inventory and properties of WIPP wastes as defined in the Baseline Inventory Report (BIR revisions 2 and 3; Ref. 17). Category 3 parameters (256 of them) were precisely known quantities, usually constants, taken from technical handbooks and the open scientific literature (e.g., the acceleration of gravity, the half-life of $U-235, \ldots$ ). Category 4 parameters ( 716 of them) were those quantities whose values (or distributions of values) could only be assigned using the professional judgments of WIPP Project investigators. Ultimately, these parameters led to $n V=57$ uncertain variables in the 1996 WIPP PA (Sect. 3).

The procedure used to assign values or distributions to the parameters in the 1996 WIPP PA is conceptualized in Fig. 1. The imprecisely known parameters are assigned values along one of the Paths $1-3$ indicated on the diagram. Path 1 was the route taken in assigning values to those Category 1 parameters for which there were three or more relevant measurements; the rationale for using Student-t distributions for the mean value of these empirically based parameters is given in Ref. 18. Parameters for which there were fewer than three measurements were treated as Category 4 parameters and processed according to the logic of Paths 2 and 3. Path 3 was the route taken in assigning values to the majority of Category 4 parameters (few investigators seemed confident of their own ability to assign an analytical form and measures of location to a parameter's distribution). The rationale for constructing a piecewiselinear empirical curmulative distribution function, as indicated at the end of Path 3, is also given in Ref. 18.

\section{Uncertain Variables}

The 1996 WIPP PA selected $n V=57$ imprecisely-known variables (i.e., parameters as used in Sect. 2) for inclusion in the analysis (Table 1). The individual variables in Table 1 (i.e., ANHBCEXP, ANHBCVGP, ..., WTAUFAIL) correspond to the elements $x_{j}$ of the vector $\mathbf{x}_{s u}$ in Eq. (1). Several criteria were used in the selection process, including observed importance in past analyses, perceived importance with respect to the 1996 WIPP PA, and general level of interest in the variable. All uncertain variables incorporated into the 1996 WIPP PA are inputs to the models used to estimate radionuclide releases to the accessible environment (Sect. 4, Ref. 1; Refs. 2 - 6). Specifically, none of the uncertain variables affect the definition of the probability space $\left(S_{s t}, \delta s t, p_{s t}\right)$ for

stochastic uncertainty (Sect. 3, Ref. 1; Ref. 11), although there is no conceptual reason that excludes $\left(\mathrm{S}_{s u} \& s u\right.$, $\left.p_{s u}\right)$ from containing such variables. 


\section{Variable Distributions}

A distribution that characterizes subjective uncertainty is indicated for each of the variables in Table 1. These distributions characterize a degree of belief as to where the appropriate value to use for each variable is located and correspond to the distributions $D_{j}$ in Eq. (2). Examples of four of these distributions are provided in Fig. 2; further, all 57 distributions are available elsewhere (App. A, Ref. 15; App. PAR, Ref. 16). The truncations associated with $A N H C O M P$ result from the restriction that the defined distribution cannot contain values that fall outside the observed range for the variable.

\section{Correlations}

Most of the variables in Table 1 are assumed to be uncorrelated. However, the pairs (ANHCOMP, ANHPRM), (HALCOMP, HALPRM) and (BPCOMP, BPPRM) are assumed to have rank correlations of $-0.99,-0.99$ and -0.75 , respectively (Fig. 3). These correlations result from a belief that the underlying physics implies that a large value for one variable in a pair should be associated with a small value for the other variable in the pair. The scatterplots in Fig. 3 result from the Latin hypercube samples described in Sect. 8, with the rank correlations within the pairs (ANHCOMP, ANHPRM), (HALCOMP, HALPRM) and (BPCOMP, BPPRM) induced with the Iman and Conover restricted pairing technique (Ref. 74; Sect. 3.2, Ref. 75).

The distributions and associated correlations indicated in Table 1 and Figs. 2 and 3 define the probability space $\left(\mathrm{S}_{s u}, b \quad s u, P_{s u}\right)$ for subjective uncertainty. The vector $\mathbf{x}_{s u}$ in Eq. (1) has the form

$$
\mathrm{x}_{\text {su }}=[A N H B C E X P, A N H B C V G P, \ldots, \text { WTAUFAIL }] \text {, }
$$

where the individual elements of $x_{s u}$ are the variables described in Table 1.

\section{Sample Size for Incorporation of Subjective Uncertainty}

The guidance in 40 CFR 194.34(d) (Ref. 76) states that "The number of CCDFs generated shall be large enough such that, at cumulative releases of 1 and 10 , the maximum CCDF generated exceeds the 99th percentile of the population of CCDFs with at least a 0.95 probability." For a Latin hypercube or random sample of size $n$, the preceding guidance is equivalent to the inequality

$$
1-0.99^{n}>0.95
$$

which results in a minimum value of 298 for $n$. In consistency with the preceding result, the 1996 WIPP PA uses an LHS of size 300 to integrate over the probability space $\left(\mathrm{S}_{s u}\right.$, \& $\left.s u, p_{s u}\right)$ for subjective uncertainty. Actually, as 
discussed in the next section, three replicated LHSs of size 100 each are used, which results in a total sample size of 300.

\section{Statistical Confidence on Mean CCDF}

The guidance in 40 CFR 194.34 (f) states that "Any compliance assessment shall provide information which demonstrates that there is at least a 95 percent level of statistical confidence that the mean of the population of CCDFs meets the containment requirements of $\S 191.13$ of this chapter." Given that Latin hypercube sampling is to be used, the confidence intervals required in $194.34(f)$ can be obtained with a replicated sampling technique proposed in Ref. 77 . In this technique, the LHS is repeatedly generated with different random seeds. These samples lead to a sequence $\bar{P}_{r}(R), r=1,2, \ldots, n R$, of estimated mean exceedance probabilities, where $\bar{P}_{r}(R)$ defines the mean CCDF obtained for sample $r$ (i.e., $\bar{P}_{r}(R)$ is the mean probability that a normalized release of size $R$ will be exceeded; see Fig. 5, Ref. 1) and $n R$ is the number of independent LHSs generated with different random seeds. Then,

$$
\bar{P}(R)=\sum_{r=1}^{n R} \bar{P}_{r}(R) / n R
$$

and

$$
S E(R)=\left\{\sum_{r=1}^{n R}\left[\bar{P}_{r}(R)-\bar{P}(R)\right]^{2} / n R(n R-1)\right\}^{1 / 2}
$$

provide an additional estimate of the mean CCDF and an estimate of the standard error associated with the mean exceedance probabilities. The $t$-distribution with $n R-1$ degrees of freedom can be used to place confidence intervals around the mean exceedance probabilities for individual $R$ values (i.e., around $\bar{P}(R)$ ). Specifically, the $1-\alpha$ confidence interval is given by $\bar{P}(R) \pm t_{1-\alpha / 2} S E(R)$, where $t_{1-\alpha / 2}$ is the $1-\alpha / 2$ quantile of the $t$-distribution with $n R-1$ degrees of freedom (e.g., $t_{1-\alpha / 2}=4.303$ for $\alpha=0.05$ and $n R=3$ ). The same procedure can also be used to place pointwise confidence intervals around percentile curves.

\section{Generation of Replicated LHSs}

The LHS program ${ }^{78.79}$ was used to produce three independently generated LHSs of size $n L H S=100$ each, for a total of 300 sample elements. Each individual replicate is an LHS of the form

$$
\mathbf{x}_{s u, k}=\left[x_{k]}, x_{k 2}, \ldots, x_{k, n l}\right], k=1,2, \ldots, n L H S=100 .
$$


In the context of the replicated sampling procedure described in Sect. 7, $n R=3$ replicates are being used, with each replicate of size 100. For notational convenience, the replicates are designated by R1, R2 and R3 for replicates 1, 2 and 3 , respectively.

At the beginning of the analysis, only the 31 variables in Table 1 that are used as input to BRAGFLO had been fully specified (i.e., their distributions $D_{j}$ had been unambiguously defined); the remaining variables now listed in Table 1 were still under development. To allow the calculations with BRAGFLO to proceed, the previously indicated LHSs were generated from $n V=75$ variables, with the first 31 variables being the then specified inputs to BRAGFLO and the remaining 44 variables being assigned uniform distributions on $[0,1]$. Later, when the additional variables in Table 1 were fully specified, the uniformly distributed variables were used to generate sampled values from them consistent with their assigned distributions. This procedure allowed the analysis to go forward while maintaining the integrity of the Latin hypercube sampling procedure for the overall analysis.

With $n V=75$ in the LHSs and 31 variables already assigned, 44 additional variables were available for incorporation into the analysis. To assure that the number of available positions in the LHSs was not exceeded, each group of investigators developing characterizations of variable uncertainty was assigned a maximum number of variables that they could elect to have incorporated into the analysis, with the sum of these maximums being less than 44. Ultimately, 26 additional variables were selected for incorporation into the analysis, which produced the 57 variables in Table 1.

The Iman and Conover restricted pairing technique ${ }^{74}$ was used to induce requested comelations and also to assure that uncorrelated variables had correlations close to zero. Due to the sequential manner in which the variables were developed, it was actually only the first 31 variables used as input to BRAGFLO that could have specified nonzero correlations. The correlations for the remaining variables were controlled in the sense that they were forced to be close to zero.

The variable pairs (ANHCOMP, ANHPRM), (HALCOMP, HALPRM) and (BPCOMP, BPPRM) were assigned rank correlations of $-0.99,-0.99$ and -0.75 , respectively (Sect. 5). Further, all other variable pairs were assigned rank correlations of zero. The restricted pairing technique was quite successful in producing these correlations (Table 2). Specifically, the correlated variables have correlations that are close to their specified values and uncorrelated variables have correlations that are close to zero.

\section{Sensitivity Analysis}

Evaluation of one or more of the models used to estimate radionuclide releases to the accessible environment (Sect. 4, Ref. 1; Ref. 2 - 6) with the LHS in Eq. (7) (see Table 6, Ref. 11) creates a mapping

$$
\left[\mathbf{x}_{s u, k} \mathbf{y}\left(\mathbf{x}_{s u . k}\right)\right], k=1,2, \ldots, n L H S,
$$


from analysis inputs (i.e., $\left.\mathbf{x}_{s u, k}\right)$ to analysis results (i.e., $\mathbf{y}\left(\mathbf{x}_{s u, k}\right)$ ), where $\mathbf{y}\left(\mathbf{x}_{s u, k}\right)$ denotes the results obtained with the model or models under consideration. A vector notation is used for $y$ because, in general, a large number of predicted results is produced by each of the models used in the 1996 WIPP PA. In addition, $\mathbf{y}\left(\mathbf{x}_{s u, k}\right)$ could also correspond to a CCDF for normalized release constructed from model results associated with $\mathbf{x}_{s u, k}$. Sensitivity analysis involves an exploration of the mapping in Eq. (8) to determine how the uncertainty in individual elements of $\mathbf{x}_{s u}$ affects the uncertainty in individual elements of $\mathbf{y}\left(\mathbf{x}_{s u}\right)$. A variety of techniques are available for use in this exploration, including examination of scatterplots, regression analysis, stepwise regression analysis, correlation and partial correlation analysis, and rank transformations of data (Sect. 3.5, Ref. 75; Sect. 6.10, Ref. 15).

Sensitivity analysis has played an important role in prior PAs for the WIPP. In particular, sensitivity analyses were carried out in support of the 1990 (Ref. 80), 1991 (Ref. 81, Vol. 4; Refs. 82, 83) and 1992 (Ref. 20, Vols. 4, 5; Ref. 84) WIPP PAs. In addition, analyses on the effects of gas generation were carried out in conjunction with the 1991 WIPP PA (Refs. $85-88$ ), and an analysis on the health effects associated with drilling intrusions was carried out in conjunction with the 1996 WIPP PA (Ref. 89). The preceding sensitivity analyses contributed to the development of the WIPP by identifying the dominant contributions to the uncertainty in the predicted behavior of the WIPP and also by providing an extensive check that the models in use were implemented correctly.

\section{Scenarios Involving Stochastic and Subjective Uncertainty}

Scenarios are usually defined to be subsets $E_{s t}$ of the sample space $S_{s t}$ for stochastic uncertainty, and scenario probabilities $p_{s t}\left(\mathrm{E}_{s t}\right)$ are defined by the function $p_{s t}$ associated with the probability space $\left(\mathrm{S}_{s t}, \& s t, p_{s t}\right)$ for stochastic uncertainty (Sect. 14, Ref. 11). This definition is consistent with the concept that a scenario is something that could happen in the future. However, this definition is also consistent with the broader concept that a scenario is simply a subset of the sample space $\mathrm{S}$ associated with an arbitrary probability space $(\mathrm{S}, \mathscr{\delta}, p)$; or to be technically correct, a scenario is an element of the set $\&$ associated with the probability space $(\mathrm{S}, \&, p)$ (Sect. 14, Ref. 11).

A probability space $\left(\mathrm{S}_{s u}, \& s u, p_{s u}\right)$ for subjective uncertainty has now been introduced. Consistent with the concept that scenarios are subsets of the sample space associated with an arbitrary probability space, scenarios could also be defined to be subsets $\mathrm{E}_{s u}$ of $\mathrm{S}_{s u}$ (i.e., elements of $\& \quad s u$ ), with corresponding probabilities given by $p_{s u}\left(\mathrm{E}_{s u}\right)$.

Although a subset $E_{s t}$ of $S_{s t}$ and also a subset $E_{s u}$ of $S_{s u}$ can be formally thought of as being scenarios in the sense of being subsets of the sample space associated with a particular probability space, $E_{s t}$ and $E_{s u}$ are very different entities. In particular, $E_{s t}$ contains vectors $x_{s t}$ of the form defined in Eq. (1) of Ref. 11, and $E_{s u}$ contains vectors $x_{s u}$ of the form defined in Eqs. (1) and (3). Further, the probability $p_{s t}\left(E_{s t}\right)$ for $E_{s t}$ characterizes the likelihood that a vector $\mathbf{x}_{s t}$ in $E_{s t}$ will match the occurrences that will take place at the WIPP over the next $10,000 \mathrm{yr}$, 
and the probability $p_{s u}\left(\mathrm{E}_{s u}\right)$ for $\mathrm{E}_{s u}$ characterizes a degree of belief that a vector $\mathbf{x}_{s u}$ in $\mathrm{E}_{s u}$ contains the appropriate values for the 57 variables in Table 1 for use in the 1996 WIPP PA. Given the difference between scenarios derived from $\mathrm{S}_{s t}$ and scenarios derived from $\mathrm{S}_{s u}$, a careful specification of what is meant by a scenario is always necessary in an analysis that involves multiple probability spaces.

The probability spaces $\left(\mathrm{S}_{s t}, \&_{s t}, p_{s t}\right)$ and $\left(\mathrm{S}_{s u}, \& \quad s u, p_{s u}\right)$ can be combined to produce an additional probability space $(\mathrm{S}, \&, p)$, where the elements $\mathrm{x}$ of the sample space $S$ are vectors of the form

$$
\mathbf{x}=\left[\mathbf{x}_{s t}, \mathbf{x}_{s u}\right], \mathbf{x}_{s t} \in \mathrm{S}_{s t}, \mathbf{x}_{s u} \in \mathrm{S}_{s u}
$$

Thus, under the convention that scenarios are subsets of the sample space associated with an arbitrary probability space, scenarios could also be defined to be sets of vectors of the form defined in Eq. (9). In this case, the definition of a scenario would involve the specification of what could occur in the future (i.e., the part of $\mathbf{x}$ defined by $\mathbf{x}_{s t}$ ) and the specification of fixed but unknown values for parameters required in the analysis (i.e., the part of $\mathbf{x}$ defined by $\left.x_{s u}\right)$.

The probability space $(\mathrm{S}, \&, p)$ can be developed from $\left(\mathrm{S}_{s t},{ }_{s t}, p_{s t}\right)$ and $\left(\mathrm{S}_{s u}, \&{ }_{s u}, p_{s u}\right)$ by defining each element $\mathrm{E}$ of $\&$ by

$$
\begin{aligned}
\mathrm{E} & =\mathrm{E}_{s t} \times \mathrm{E}_{s u} \\
& =\left\{\mathbf{x}: \mathbf{x}=\left[\mathbf{x}_{s t}, \mathbf{x}_{s u}\right], \mathbf{x}_{s t} \in \mathrm{E}_{s t}, \mathbf{x}_{s u} \in \mathrm{E}_{s u}\right\},
\end{aligned}
$$

where $\mathrm{E}_{s t} \in \mathcal{S}_{s t}$ and $\mathrm{E}_{s u} \in \mathscr{\delta}_{s u}$. If the probability spaces $\left(\mathrm{S}_{s t}, \&_{s t}, p_{s t}\right)$ and $\left(\mathrm{S}_{s u}, \mathscr{\delta}_{s u}, p_{s u}\right)$ are independent (i.e., the occurrence of a particular element $\mathrm{x}_{s t}$ of $\mathrm{S}_{s t}$ does not affect the definition of $\left(\mathrm{S}_{s u}, \&_{s u}\right.$, $\left.p_{s u}\right)$, and the occurrence of a particular element $\mathrm{x}_{s u}$ of $\mathrm{S}_{s u}$ does not affect the definition of $\left.\left(\mathrm{S}_{s t}, \& s t, p_{s i}\right)\right)$, then

$$
p(\mathrm{E})=p\left(\mathrm{E}_{s t} \times \mathrm{E}_{s u}\right)=p_{s l}\left(\mathrm{E}_{s l}\right) p_{s t}\left(\mathrm{E}_{s u}\right)
$$

If $\left(\mathrm{S}_{s t}, \& \quad s t, p_{s t}\right)$ and $\left(\mathrm{S}_{s u}, \& s u, p_{s u}\right)$ are not independent, then a more complicated definition for $p$ is required, with the exact nature of this definition being a function of the dependencies that exist between $\left(\mathrm{S}_{s t}, b_{s t}, p_{s t}\right)$ and $\left(\mathrm{S}_{s u}, \&_{s u}, p_{s u}\right)$.

In the 1996 WIPP PA, $\left(\mathrm{S}_{s t}, \&_{s t}, p_{s t}\right)$ and $\left(\mathrm{S}_{s u}, \&_{s u}, p_{s u}\right)$ are independent, with the result that the relationship in Eq. (11) holds. This would not be the case if a parameter required in the definition of $\left(\mathrm{S}_{s t}, b_{s l}, p_{s t}\right)$ was treated as being uncertain and thus included in $\mathbf{x}_{s u}$. For example, a more complex definition for $p$ in Eq. (11) would be required if the drilling rate in Eqs. (3) - (5) of Ref. 11 was treated as being uncertain. Although none of the quantities used in the definition of $\left(\mathrm{S}_{s t}, \& s t, p_{s t}\right)$ in the 1996 WIPP PA were considered to be uncertain, such uncertainties were considered in a verification analysis performed at SNL for the U.S. EPA (Ref. 90); in particular, 
the probability that a drilling intrusion would penetrate pressurized brine (Sect. 5, Ref. 11) was treated as being uncertain and included in the definition of $\mathbf{x}_{s u}$.

As described in conjunction with the probability spaces $\left(\mathrm{S}_{s t}, \&_{s t}, p_{s t}\right),\left(\mathrm{S}_{s u}, \& \quad s u, p_{s u}\right)$ and $\left(\mathrm{S}=\mathrm{S}_{s t} \times \mathrm{S}_{s u}, \&\right.$ ,$p$ ), the concept of a scenario is consistent in the sense of being a subset of a sample space and yet can involve quite different entities due to the different probability spaces potentially under consideration. Thus, when the use of scenarios is discussed, it is important to specify clearly which of many possible probability spaces is under consideration.

Unless specified otherwise, use of the term scenario in the 1996 WIPP PA refers to subsets of the sarmple space $S_{s t}$ for stochastic uncertainty (Sect. 14, Ref. 11). However, due to the use of Monte Carlo procedures to incorporate the effects of stochastic and subjective uncertainty into the 1996 WIPP PA, the use of terminology related to scenarios does not play a large role in the description of this analysis.

\section{Discussion}

The characterization of subjective uncertainty in the 1996 WIPP PA has been described. In particular, subjective uncertainty is characterized by a probability space $\left(\mathrm{S}_{s u}, \&_{s u}, p_{s u}\right)$ and leads to a distribution of the CCDFs specified by the EPA in 40 CFR 191 (Refs. 91, 92). In turn, the individual CCDFs in this distribution arise from a probability space $\left(\mathrm{S}_{s t}, \&_{s t}, p_{s t}\right)$ for stochastic uncertainty. ${ }^{11}$ The location of the distribution of CCDFs relative to the boundary line specified in 40 CFR 191 provides a measure of the confidence with which it is believed that this regulation will be met.

The intent of the 1996 WIPP PA was to use the probability space $\left(\mathrm{S}_{s u}, \& s u, p_{s u}\right)$ in the development of an unbiased representation of the subjective, or state of knowledge, uncertainty in its outcomes. Thus, the goal in assigning the distributions that defined $\left(\mathrm{S}_{s u}, \&_{s u}, p_{s u}\right)$ was to neither deliberately overestimate nor deliberately underestimate the possible values for individual variables. Such assignments then lead to unbiased estimates of the uncertainty in the outcomes of the analysis. The need for such uncertainty estimates in analyses supporting important decisions has been widely emphasized (Sect. 6, Ref. 1).

There is one important area in which the 1996 WIPP PA did not attempt to assess the uncertainty in its inputs. The EPA gave very specific guidance in 40 CFR 194 (Ref. 76) on how the drilling and mining rates should be determined in assessing compliance with 40 CFR 191 (Sects. 2, 8, Ref. 11). As a result, these two rates, which play an important role in the definition of the probability space $\left(\mathrm{S}_{s t}, \&_{s t}, p_{s t}\right)$ for stochastic uncertainty, were assigned fixed values rather than distributions. Thus, the 1996 WIPP PA does not incorporate the possible effects of uncertainty in these two analysis inputs; rather, the outcomes of the PA are conditional on the values specified by the EPA. 
A concern is sometimes expressed that analysts will be unduly optimistic when asked to characterize the uncertainty in analysis inputs (i.e., will tend to supply variable values that will cause analysis outcomes to appear to be more favorable than they should be). The experience of the authors is that the opposite is the case. In particular, there is a tendency on the part of the analysts to supply conservative values (i.e., values that cause analysis outcomes to appear to be less favorable than they should be). Thus, when a characterization of subjective uncertainty is developed, it is important for everyone involved to understand that the intent is to develop an accurate (i.e., honest) representation of the current state of knowledge that is neither unduly optimistic nor unduly pessimistic. Without such a representation, it is difficult to interpret and use the uncertainty and sensitivity analysis results that arise from a propagation of subjective uncertainty.

The results of propagating and analyzing the effects of subjective uncertainty in the 1996 WIPP PA are presented in a sequence of additional articles. ${ }^{3-6,12-14}$

\section{Acknowledgment}

Work performed for Sandia National Laboratories (SNL), which is a multiprogram laboratory operated by Sandia Corporation, a Lockheed Martin Company, for the United States Department of Energy under contract DE-AC04-94AL85000. Review provided at SNL by M. Chavez, C. Crawford and J.W. Garner. Editorial support provided by L. Harrison, T. Allen and H. Radke of Tech Reps, Inc.

\section{References}

1. Helton, J.C., Anderson, D.R., Basabilvazo, G., Jow, H.-N., \& Marietta, M.G., Conceptual Structure of the 1996 Performance Assessment for the Waste Isolation Pilot Plant, Reliability Engineering and System Safety (in this issue).

2. Vaughn, P., Bean, J.E., Helton, J.C., Lord, M.E., MacKinnon, R.J., \& Schreiber, J.D., Representation of TwoPhase Flow in the Vicinity of the Repository in the 1996 Performance Assessment for the Waste Isolation Pilot Plant, Reliability Engineering and System Safety (in this issue).

3. Berglund, J.W., Garner, J.W., Helton, J.C., Johnson, J.D., \& Smith, L. N., Direct Releases to the Surface and Associated Complementary Cumulative Distribution Functions in the 1996 Performance Assessment for the Waste Isolation Pilot Plant: Cuttings, Cavings and Spallings, Reliability Engineering and System Safety (in this issue).

4. Stoelzel, D.M., O'Brien, D.G., Garner, J.W., Helton, J.C., Johnson, J.D., \& Smith, L.N., Direct Releases to the Surface and Associated Complementary Cumulative Distribution Functions in the 1996 Performance Assessment for the Waste Isolation Pilot Plant: Direct Brine Releases, Reliability Engineering and System Safety (in this issue).

5. Stockman, C.T., Garner, J.W., Helton, J.C., Johnson, J.D., Shinta, A., \& Smith, L.N., Radionuclide Transport in the Vicinity of the Repository and Associated Complementary Cumulative Distribution Functions in the 1996 
Performance Assessment for the Waste Isolation Pilot Plant, Reliability Engineering and System Safety (in this issue).

6. Ramsey, J.L., Blaine, R., Garner, J.W., Helton, J.C., Johnson, J.D., Smith, L.N., \& Wallace, M., Radionuclide and Colloid Transport in the Culebra Dolomite and Associated Complementary Cumulative Distribution Functions in the 1996 Performance Assessment for the Waste Isolation Pilot Plant, Reliability Engineering and System Safety (in this issue).

7. Larson, K.W., Development of the Conceptual Models for Chemical Conditions and Hydrology Used in the 1996 Performance Assessment for the Waste Isolation Pilot Plant, Reliability Engineering and System Safety (in this issue).

8. Froehlich, G.K., Ogden, H.C., \& Byle, K.A., Software Quality Assurance in the 1996 Performance Assessment for the Waste Isolation Pilot Plant, Reliability Engineering and System Safety (in this issue).

9. Froehlich, G.K., Williamson, C.M., \& Ogden, H.C., Computational Environment and Software Configuration Management of the 1996 Performance Assessment for the Waste Isolation Pilot Plant, Reliability Engineering and System Safety (in this issue, 1999).

10. McKay, M.D., Beclman, RJ., \& Conover, W.J., A Comparison of Three Methods for Selecting Values of Input Variables in the Analysis of Output from a Computer Code, Technometrics, 1979, 21, 239-245.

11. Helton, J.C., Davis, F.J., \& Johnson, J.D., Characterization of Stochastic Uncertainty in the 1996 Performance Assessment for the Waste Isolation Pilot Plant, Reliability Engineering and System Safety (in this issue).

12. Helton, J.C., Bean, J.E., Economy, K., Garner, J.W., MacKinnon, R.J., Miller, J., Schreiber, J.D., \& Vaughn, P., Uncertainty and Sensitivity Analysis for Two-Phase Flow in the Vicinity of the Repository in the 1996 Performance Assessment for the Waste Isolation Pilot Plant: Undisturbed Conditions, Reliability Engineering and System Safery (in this issue).

13. Helton, J.C., Bean. J.E., Economy, K., Gamer, J.W., MacKinnon, R.J., Miller, J., Schreiber, J.D., \& Vaughn, P., Uncertainty and Sensitivity Analysis for Two-Phase Flow in the Vicinity of the Repository in the 1996 Performance Assessment for the Waste Isolation Pilot Plant: Disturbed Conditions, Reliability Engineering and System Safety (in this issue).

14. Helton, J.C., Anderson, D.R, Basabilvazo, G., Jow, H.-N., \& Marietta, M.G., Summary Discussion of the 1996 Performance Assessment for the Waste Isolation Pilot Plant. Reliability Engineering and System Safery (in this issue).

15. Helton, J.C., Bean, J.E., Berglund, J.W., Davis, F.J., Economy, K., Garner, J.W., Johnson, J.W., MacKinnon, R.J., Miller, J., O'Brien D.G., Ramsey, J.L., Schreiber, J.D., Shinta, A., Smith, L.N., Stoelzel, D.M., Stockman, C., \& Vaughn, P., Uncenainty and Sensitivity Analysis Results Obtained in the 1996 Performance Assessment for the Waste Isolation Pilot Plant, SAND98-0365, Sandia National Laboratories, Albuquerque, NM, 1998.

16. U.S. Department of Energy, Title 40 CFR Part 191 Compliance Certification Application for the Waste Isolation Pilot Plant, DOE/CAO-1996-2184, Volumes I-XXI, U.S. Department of Energy, Carlsbad Area Office, Carlsbad, NM, 1996.

17. U.S. Department of Energy, Transuranic Waste Baseline Inventory Report (Revisions 2 and 3) DOE/CAO-951121, Carlsbad, NM. 1995-1996. 
18. Tierney, M.S., Constructing Probability Distributions of Uncertain Variables in Models of the Performance of the Waste Isolation Pilot Plant: The 1990 Performance Simulations, SAND90-2510, Sandia National Laboratories, Albuquerque, NM, 1990.

19. Howarth, S.M., \& Christian-Frear, T., Porosity, Single-Phase Permeability, and Capillary Pressure Data from Preliminary Laboratory Experiments on Selected Samples from Marker Bed 139 at the Waste Isolation Pilot Plant, SAND94-0472/1/2/3, Sandia National Laboratories, Albuquerque, NM, 1997.

20. WIPP PA (Performance Assessment), Preliminary Performance Assessment for the Waste Isolation Pilot Plant, December 1992, SAND92-0700/1-5, Volumes 1-5, Sandia National Laboratories, Albuquerque, NM, 19921993.

21. Saulnier, G.J., Jr., Domski, P.S., Palmer, J.B., Roberts, R.M., Stensrud, W.A., \& Jensen, A.L., WhPP Salado Hydrology Program Data Report \#1, SAND90-7000, Sandia National Laboratories, Albuquerque, NM, 1991.

22. Stensrud, W.A., Dale, T.F., Domski, P.S., Palmer, J.B., Roberts, R.M,. Fort, M.D., Saulnier, Jr., G.J., \& Jensen, A.L., Waste Isolation Pilot Plant Salado Hydrology Program Data Report \#2, SAND92-7072, Sandia National Laboratories, Albuquerque, NM, 1992.

23. Thompson, T.W., Coons, W.E., Krumbansl, J.L., \& Hansen, F.D., Inadvertent Intrusion Borehole Permeability, Final Draft. May 20, 1996. Sandia WIPP Central Files WPO \# 41131, Sandia National Laboratories, Albuquerque, NM, 1996.

24. Freeze, G.F. Non-Salado: Castile Brine Reservoir Rock Compressibility. Records package. Sandia WIPP Central Files WPO \# 31084, Sandia National Laboratories, Albuquerque, NM, 1996.

25. Freeze, G., \& Larson, K., Initial Pressure in the Castile Brine Reservoir. Memo to M. Tiemey, March 20, 1996. Sandia WIPP Central Files WPO \# 37148, Sandia National Laboratories, Albuquerque, NM, 1996.

26. Freeze, G.F., Non-Salado: Castile Brine Reservoir Permeability. Records package. Sandia WIPP Central Files WPO \# 31070, Sandia National Laboratories, Albuquerque, NM, 1996.

27. Popielak, R.S., Beauheim, R.L., Black, S.R., Coons, W.E., Ellingson, C.T., \& Olsen, R.L., Brine Reservoirs in the Castile Formation, Waste Isolation Pilot Plant (WIPP) Project, Southeastern New Mexico. TME-3153. U.S. Department of Energy, Waste Isolation Pilot Plant, Albuquerque, NM, 1983.

28. Powers, D.W., Sigda, J.M., \& Holt, R.M., Probability of Intercepting a Pressurized Brine Reservoir Under the WIPP, Sandia WIPP Central Files WPO \# 40199, Sandia National Laboratories, Albuquerque, NM, 1996.

29. Larson, K., Tracing the Source: The $32,000 \mathrm{~m}^{3}$ Reservoir Volume Used in Determination of GRIDFLO Parameter Probabilities, Sandia WIPP Central Files WPO \# 44401 attachment. Sandia National Laboratories, Albuquerque, NM, 1997.

30. Swift, P.N., Larson, K.W., \& Beauheim, R.L., Treatment of Castile Brine Reservoir in the 1996 CCA Performance Assessment. Memo to L.E. Shephard and M.S.Y. Chu, October 3, 1996. Sandia WIPP Central Files WPO \# 41885, Sandia National Laboratories, Albuquerque, NM, 1996.

31. Meigs, L., \& McCord, J., Non-Salado: Advective Porosity for the Culebra Dolomite (WPO \# 37227). Memo to J. Ramsey, June 6, 1996. Sandia WIPP Central Files WPO \# 38939, Sandia National Laboratories, Albuquerque, NM, 1996.

32. Meigs, L., Non-Salado: Culebra Advective Porosity. Sandia WIPP Central Files WPO \# 37227, Records package, Sandia National Laboratories, Albuquerque, NM, 1996. 
33. Meigs, L., Non-Salado: Culebra Half Matrix Block Length. Sandia WIPP Central Files WPO \# 37225, Records package, Sandia National Laboratories, Albuquerque, NM, 1996.

34. Meigs, L., \& McCord, J., Non-Salado: Culebra Half Matrix Block Length (WPO \# 37225). Memo to J. Ramsey, June 7, 1996. Sandia WIPP Central Files WPO \# 38928, Sandia National Laboratories, Albuquerque, NM, 1996.

35. Brush, L.H., Revised Free-Solution Tracer Diffusion Coefficients $\left(D_{\text {sol }} S\right)$ for Dissolved $\mathrm{Pu}, \mathrm{Am}, \mathrm{U}, \mathrm{Th}, \mathrm{Np}$, $\mathrm{Cm}$, and $\mathrm{Ra}$ in Boreholes and the Culebra for Use in PA Calculations to Support the WIPP CCA, Laboratory Column Experiments for Radionuclide Adsorption Studies of the Culebra Dolomite Member of the Rustler Formation. D.A. Lucero, G.O. Brown, and C.E. Heath. SAND97-1763, Sandia National Laboratories, Albuquerque, NM, 1998, D-4 through D-8.

36. Meigs, L., Non-Salado: Diffusive Porosity for the Culebra Dolomite. Memo to J. Ramsey, June 6, 1996. Sandia WIPP Central Files WPO \# 38773, Sandia National Laboratories, Albuquerque, NM, 1996.

37. Meigs, L., Non-Salado: Culebra Diffusive Porosity. Sandia WIPP Central Files WPO \# 37228, Records package, Sandia National Laboratories, Albuquerque, NM, 1996.

38. LaVenue, A.M. Analysis of the Generation of Transmissivity Fields for the Culebra Dolomite, Sandia WIPP Central Files WPO \# 40517, Sandia National Laboratories, Albuquerque, NM, 1996.

39. Wallace, M.G., Phase II FEP, NS-11, Subsidence Associated with Mining Inside or Outside the Controlled Area. Records package, Sandia WIPP Central Files WPO \# 40816, Sandia National Laboratories, Albuquerque, NM, 1996.

40. Wallace, M.G., Distribution for Non-Salado Parameter for SECOFL2D: Mining Transmissivity Multiplier. Memo to M. Tiemey, April 18, 1996. Sandia WIPP Central Files WPO \# 39355, Sandia National Laboratories, A buquerque, NM, 1996.

41. Wallace, M.G., Mining Transmissivity Multiplier. Records Package. Sandia WIPP Central Files WPO \# 36489, Sandia National Laboratories, Albuquerque, NM, 1996.

42. Corbet, T., \& Swift, P., Distribution for Non-Salado Parameter for SECOFL2D: Climate Index. Memo to M.S. Tierney, April 12, 1996. Sandia WIPP Central Files WPO\# 36425, Segment 2. Sandia National Laboratories, Albuquerque, NM, 1996.

43. Corbet, T., \& Swift, P., Parameters Required for SECOFL2D: Climate Index, Record package, Sandia WIPP Central Files WPO \# 36425, Sandia National Laboratories, Albuquerque, NM, 1996.

44. Christian-Frear, T.L., Salado Halite Rock Compressibility from Room Q Analysis. Records packages, Sandia WIPP Central Files WPO \# 30598, WPO \# 31220, Sandia National Laboratories, Albuquerque, NM, 1996.

45. Howarth, S.M., Salado Halite Porosity. Records package, Sandia WIPP Central Files WPO \# 30601, Sandia National Laboratories, Albuquerque, NM, 1996.

46. Davies, P., \& Beauheim, R., Changes to the Parameter Records Package and Form \# 464 for Far-Field Permeability of Salado Halites. Memo to M. Tierney, March 7, 1996. Sandia WIPP Central Files WPO \#36772, Sandia National Laboratories, Albuquerque, NM, 1996.

47. Domski, P., Salado: Halite Permeability, Records Package, Sandia WIPP Central Files WPO \# 31218, Sandia National Laboratories, Albuquerque, NM, 1996. 
48. Christian-Frear, T.L., Salado Halite Permeability from Room Q Analysis. Records Package, Sandia WIPP Central Files WPO $\frac{\|}{\pi} 30721$, Sandia National Laboratories, Albuquerque, NM, 1996.

49. Domski, P., Salado: Halite Pressure, Records Package, Sandia WIPP Central Files WPO \# 31221, Sandia National Laboratories, Albuquerque, NM, 1996.

50. Kelley, V.A., Jones, T.L., \& Ogintz, J.B., WIPP Seal System Parameters for Performance Assessment BRAGFLO Compliance Calculations. Memo to L.D. Hurtado, January 15, 1996, Sandia WIPP Central Files WPO \# 30995, Sandia National Laboratories, Albuquerque, NM, 1996.

51. Kelley, V.A., Jones, T.L., \& Ogintz, J.B., WIPP Shaft Seal System Parameters Documentation to Support Performance Assessment BRAGFLO Compliance Calculations. Internal Memo to L.D. Hurtado. March 22, 1996. Sandia WIPP Central Files WPO \# 40258, Sandia National Laboratories, Albuquerque, NM, 1996.

52. Hurtado, LD., Correction of Lambda Distribution. Memo to M. Tierney, February 12, 1996. Sandia WIPP Central Files WPO \# 32287, Sandia National Laboratories, Albuquerque, NM, 1996.

53. Repository Isolation Systems Department, Waste Isolation Pilot Plant Shaft Sealing System Compliance Submittal Design Report. SAND96-1326/1-2. Vols. 1-2. Sandia National Laboratories, Albuquerque, NM, 1996.

54. Knowles, M.K., Borns, D., Fredrich, J., Holcomb, D., Price, R., Zeuch, D., Dale, T., \& Van Pelt, R.S., Testing the Disturbed Zone Around a Rigid Inclusion in Salt, The Mechanical Behavior of Salt, Proceedings of the Fourth Conference, Ecole Polytechniquet, Montreal, Quebec, Canada, June 17 and 18, 1996. SAND95-1151C, Eds. M. Aubertin \& H.R. Hardy, Jr., Clausthal-Zellerfield, Germany: TTP Trans Tech Publications, pp. 175-188. $1998 .$.

55. Vaughn, P, \& McArthur, D., CUMPROB Parameter Definition and Usage. Memo to M. Tiemey, May 20, 1996. Sandia WIPP Central Files WPO \# 37542, Sandia National Laboratories, Albuquerque, NM, 1996.

56. Mayer, G., Jacobs, F., \& Wittmann, F.H., Experimental Determination and Numerical Simulation of the Permeability of Cementitious Materials, Nuclear Engineering and Design, 1992, 138(2), 171-177." Records package, Sandia National Laboratories, Albuquerque, NM. 1992.

57. Wang, Y., and Brush, L., Estimates of Gas-Generation Parameters for the Long-Term WIPP Performance Assessment Memo to M. Tierney, January 26, 1996. Sandia WIPP Central Files WPO \# 35162, Sandia National Laboratories, Albuquerque, NM, 1996.

58. Wang, Y., \& Brush, L., Modify the Stoichiometric Factor $y$ in BRAGFLO to Include the Effect of MgO Added to WIPP Repository as Backfill. Memo to Martin Tierney, February 23, 1996. Sandia WIPP Central Files WPO \# 32286, Sandia National Laboratories, Albuquerque, NM, 1996.

59. Tierney, M.S., Reasons for Choice of the PROBDEG Parameter (id nos: 2824 and 2823) on February 22, 1996. Memo to file, March 29, 1996. Sandia WIPP Central Files WPO \# 34881, Sandia National Laboratories, Albuquerque, NM, 1996.

60. Berglund, J.W., Analysis Package for the Cuttings and Spalling Calculations (Task 5 and 6) of the Performance Assessment Analyses Supporting the Compliance Certification Application., Sandia Central Files WPO \# 40521, Sandia National Laboratories, Albuquerque, NM, 1996.

61. Berglund, J., Parameters Required for the CUTTINGS_S Code for Use in WIPP Performance Assessment. Memo to M.S. Tierney, April 1, 1996. Sandia WIPP Central Files WPO \# 36766, Sandia National Laboratories, Albuquerque, NM, 1996.

62. Weiner, R.F., Documentation Package for Oxidation State Distribution of Actinides in the Repository. Records Package, Sandia WIPP Central Files WPO \# 35194, Sandia National Laboratories, Albuquerque, NM, 1996. 
63. Stockman, C., Implementation of Chemistry Parameters in PA. Reducing the Number of Sampled Parameters. Memo to M. Tierney, April 16, 1996. Sandia WIPP Central Files WPO \# 37536 attachment. Sandia National Laboratories, Albuquerque, NM, 1996.

64. Papenguth, H.W., Development of Parameter Values Describing Colloidal Actinide Retardation in the Culebra Dolomite, Document in Records Package: Colloidal Actinide Retardation Parameters. Sandia WIPP Central Files WPO \# 38173. Sandia National Laboratories, Albuquerque, NM, 1996.

65. Papenguth, H.W., \& Moore, R.C., Mobile-Colloidal-Actinide Source Term, 3. Humic Substances. Records package. Sandia WIPP Central Files WPO \# 35855, Sandia National Laboratories, Albuquerque, NM, 1996.

66. Papenguth, H.W., \& Moore, R.C., Rationale for Definition of Parameter Values for Humic Substances. Sandia WIPP Central Files WPO \# 35855, Attachment A. Sandia National Laboratories, Albuquerque, NM, 1996.

67. Vaughn, P., WAS_AREA and REPOSIT SAT_RBRN Distribution. Memo with attachments to M. Tierney, February 13, 1996. Sandia WIPP Central Files WPO \# 34902, Sandia National Laboratories, Albuquerque, NM, 1996.

68. O'Brien, D.G., Critical Gas Saturation Recommendations for WIPP. cc: Letter Report D. O'Brien to D.M. Stoelzel, November 15, 1995. Sandia WIPP Central Files WPO \# 38769, Solutions Engineering, Littleton, CO, 1995.

69. Siegel, M.D., Solubility Parameters for Actinide Source Term Look-Up Tables. Sandia WIPP Central Files WPO \# 35835. Records package, Sandia National Laboratories, Albuquerque, NM, 1996.

70. Stockman, C., Proposed Method of Implementation of Updated Solubility Distributions. Memo to M. Martell, May 10, 1996. Sandia WIPP Central Files WPO \# 37545, Sandia National Laboratories, Albuquerque, NM, 1996.

71. Stockman, C., Shinta, A., \& Garner, J.W., Analysis Package for the Salado Transport Calculations (Task 2) of the Performance Assessment Analysis Supporting the Compliance Certification Application (CCA), AP-02 3 . Analysis package, Sandia WIPP Central Files WPO \# 40515, Sandia National Laboratories, Albuquerque, NM, 1996.

72. Bynum, R.V., Revised Update of Uncertainty Range and Distribution for Actinide Solubility to be Used in CCA NUTS Calculations. Memo to M.S. Tierney and C. Stockman, May 23, 1996, Sandia WIPP Central Files WPO \# 37791, Sandia National Laboratories, Albuquerque, NM, 1996.

73. Berglund, J., Effective Shear Resistance to Erosion TAUFAIL. Memo to B.M. Butcher, October 28, 1996. Sandia WIPP Central Files WPO \# 35695 attachment. Sandia National Laboratories, Albuquerque, NM, 1996.

74. Iman, R.L., \& Conover, W.J. A Distribution-Free Approach to Inducing Rank Correlation Among Input Variables, Communications in Statistics: Simulation and Computation, 1982, B11(3), 311-334.

75. Helton, J.C., Uncertainty and Sensitivity Analysis Techniques for Use in Performance Assessment for Radioactive Waste Disposal, Reliability Engineering and System Safety, 1993, 42(2-3), 327-367.

76. U.S. Environmental Protection Agency, 40 CFR Part 194: Criteria for the Certification and Re-Certification of the Waste Isolation Pilot Plant's Compliance With the 40 CFR Part 191 Disposal Regulations; Final Rule, Federal Register, 1996, 61(28), 5224-5245.

77. Iman, R.L., Statistical Methods for Including Uncertainties Associated with the Geologic Isolation of Radioactive Waste Which Allow for a Comparison with Licensing Criteria, Proceedings of the Symposium on Uncertainties Associated with the Regulation of the Geologic Disposal of High-Level Radioactive Waste, 9-13, March 1981. Ed. D.C. Kocher. NUREG/CP-0022, CONF-810372. U.S. Nuclear Regulatory Commission. Washington, DC. Directorate of Technical Information and Document Control. pp. 145-157. 1982. 
78. Iman, R.L., \& Shortencarier, M.J., A Fortran 77 Program and User's Guide for the Generation of Latin Hypercube and Random Samples for Use with Computer Models, SAND83-2365, Sandia National Laboratories, Albuquerque, NM, 1984.

79. Smith, L.N., User's Manual for LHS, Version 2.4.1, Sandia WIPP Central Files WPO \#30732, Sandia National Laboratories, Albuquerque, NM, 1996.

80. Helton, J.C., Garner, J.W., McCurley, R.D., \& Rudeen, D.K., Sensitivity Analysis Techniques and Results for Performance Assessment at the Waste Isolation Pilot Plant, SAND90-7103, Sandia National Laboratories, Albuquerque, NM, 1991.

81. WIPP PA (Performance Assessment) Division, Preliminary Comparison with 40 CFR Part 191, Subpart B for the Waste Isolation Pilot Plant, December 1991, Volumes 1-4, SAND91-0893/1-4, Sandia National Laboratories, Albuquerque, NM, 1991-1992.

82. :Helton, J.C., Garner, J.W., Marietta, M.G., Rechard, R.P., Rudeen, D.K., \& Swift, P.N. Uncertainty and Sensitivity Analysis Results Obtained in a Preliminary Performance Assessment for the Waste Isolation Pilot Plant, Nuclear Science and Engineering, 1993, 114, 286-331.

83. Helton, J.C., Anderson, D.R., Baker, B.L., Bean, J.E., Berglund, J.W., Beyeler, W. Garner, J.W., Iuzzolino, H.J., Marietta, M.G., Rechard, R.P., Roache, P.J., Rudeen, D.K., Schreiber, J.D., Swift, P.N., Tierney, M.S., \& Vaughn, P., Effect of Alternative Conceptual Models in a Preliminary Performance Assessment for the Waste Isolation Pilot Plant, Nuclear Engineering and Design, 1995, 154(3), 251-344.

84. Helton, J.C., Anderson, D.R., Baker, B.L., Bean, J.E., Berglund, J.W., Beyeler, W., Economy, K., Garner, J.W., Hora, S.C., Iuzzolino, H.J., Knupp, P., Marietta, M.G., Rath, J., Rechard, R.P., Roache, P.J., Rudeen, D.K., Salañ, K., Schreiber, J.D., Swift, P.N., Tiemey, M.S., \& Vaughn, P., Uncertainty and Sensitivity Analysis Results Obtained in the 1992 Performance Assessment for the Waste Isolation Pilot Plant, Reliability Engineering and System Safety, 1996, 51(1), 53-100.

85. Helton, J.C., Bean, J.E., Butcher, B.M., Garner, J.W., Schreiber, J.D., Swift, P.N., \& Vaughn, P., Uncertainty and Sensitivity Analysis for Gas and Brine Migration at the Waste Isolation Pilot Plant, May 1992, SAND922013, Sandia National Laboratories, Albuquerque, NM, 1993.

86. Helton, J.C., Bean, J.E., Butcher, B.M., Garner, J.W., Schreiber, J.D., Swift, P.N., \& Vaughn, P., Uncertainty and Sensitivity Analysis for Gas and Brine Migration at the Waste Isolation Pilot Plant: Fully Consolidated Shaft, Nuclear Science and Engineering, 1996, 122(1), 1-31.

87. Helton, J.C., Bean, J.E., Butcher, B.M., Garner, J.W., Schreiber, J.D., Swift, P.N., \& Vaughn, P., Uncertainty and Sensitivity Analysis for Gas and Brine Migration at the Waste Isolation Pilot Plant: Permeable Shaft with Panel Seals, Journal of Hazardous Materials, 1996, 45(2-3), 107-139.

88. Helton, J.C., Bean, J.E., Butcher, B.M., Gamer, J.W., Schreiber, J.D., Swift, P.N., \& Vaughn, P., Uncertainty and Sensitivity Analysis for Gas and Brine Migration at the Waste Isolation Pilot Plant: Permeable Shaft without Panel Seals, Reliability Engineering and System Safety, 1997, 57(3), 299-316.

89. Helton, J.C., Johnson, J.D., Jow, H.-N., McCurley, R.D., \& Rahal, L.J., Stochastic and Subjective Uncertainty in the Assessment of Radiation Exposure at the Waste Isolation Pilot Plant, Human and Ecological Risk Assessment, 1998, 4(2), 469-526.

90. MacKinnon, R.J., Freeze, G., \& Jow, H., Summary of EPA-Mandated Performance Assessment Verification Test (Replicate 1) and Comparison with the Compliance Certification Application Calculations, Technical Data Package, Sandia WIPP Central Files WPO \# 46674, Sandia National Laboratories, Albuquerque, NM, 1997. 
91. U.S. Environmental Protection Agency, Environmental Standards for the Management and Disposal of Spent Nuclear Fuel, High-Level and Transuranic Radioactive Wastes; Final Rule, 40 CFR Part 191, Federal Register, $1985,50(182), 38066-38089$.

92. U.S. Environmental Protection Agency, Environmental Radiation Protection Standards for the Management and Disposal of Spent Nuclear Fuel, High-Level and Transuranic Radioactive Wastes; Final Rule, 40 CFR Part 191, Federal Register, 1993, 58(242), 66398-66416. 
Figure Captions

Fig. 1. Conceptualization of procedure for assigning values to parameters in the 1996 WIPP PA.

Fig. 2. Examples of uncertain variables, their associated distributions, and sampled values obtained with a Latin hypercube sample (Ref. 10; see Sect. 11) of size 100.

Fig. 3. Scatterplots illustrating correlations within the pairs (ANHCOMP, ANHPRM), (HALCOMP, HALPRM) and (BPCOMP, BPPRM). 
Identify a Physical Parameter in Computational Models

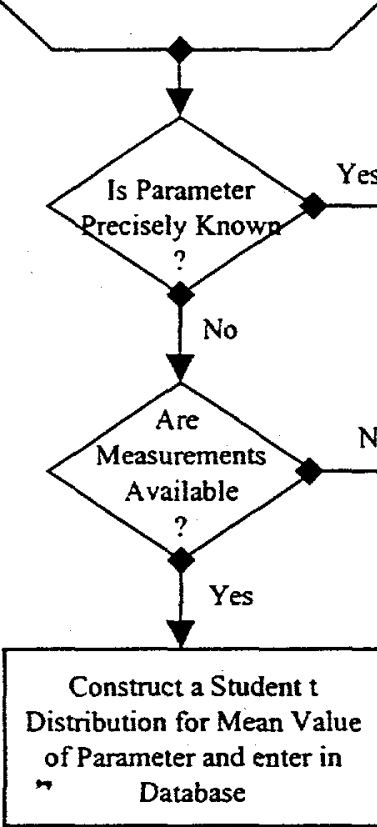

Path 1
Path 2

Enter Constant

Parameter in

Database

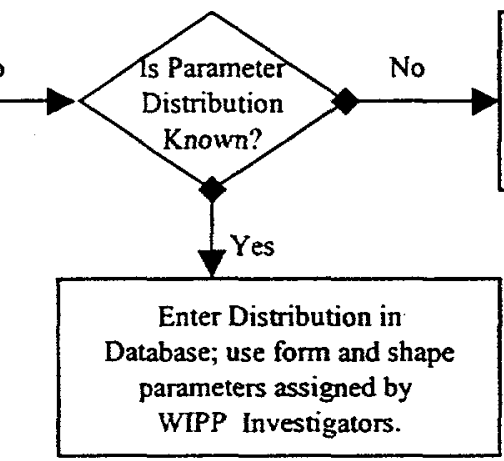

Using Professional Judgement, WIPP Investigators estimate Range and, as possible, Percentile Points of unknown distribution.

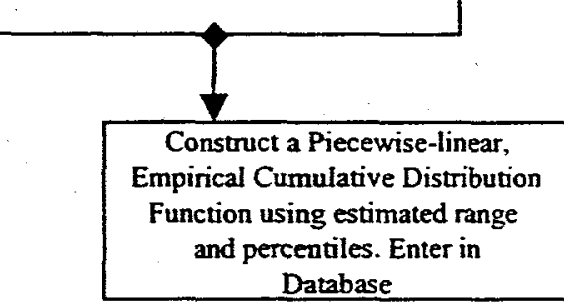

Database

Path 3

Fig. 1. Conceptualization of procedure for assigning values to parameters in the 1996 WIPP PA. 

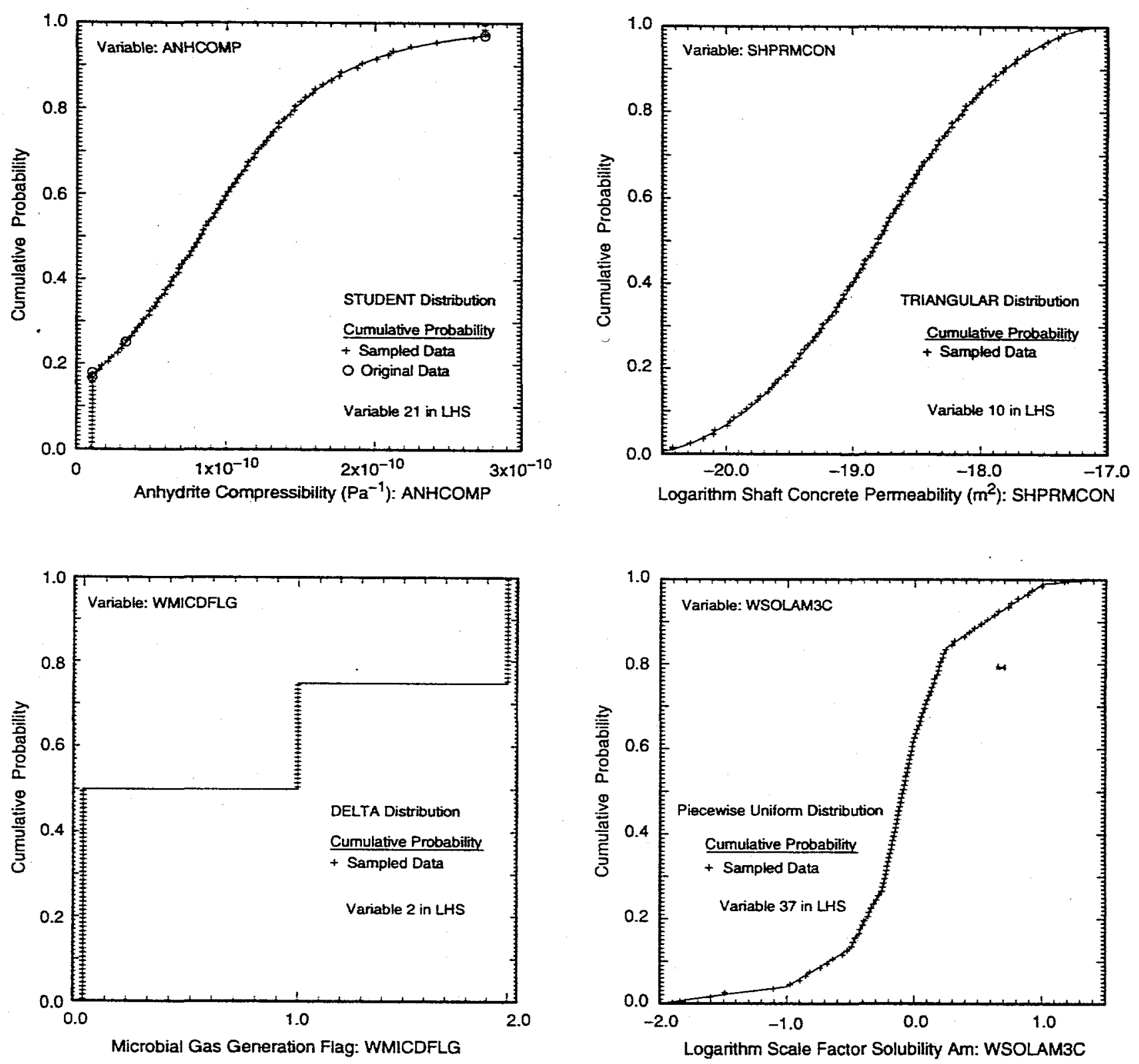

TR1-6342-5173-1

Fig. 2. Examples of uncertain variables, their associated distributions, and sampled values obtained with a Latin hypercube sample (Ref. 10; see Sect. 11) of size 100. 

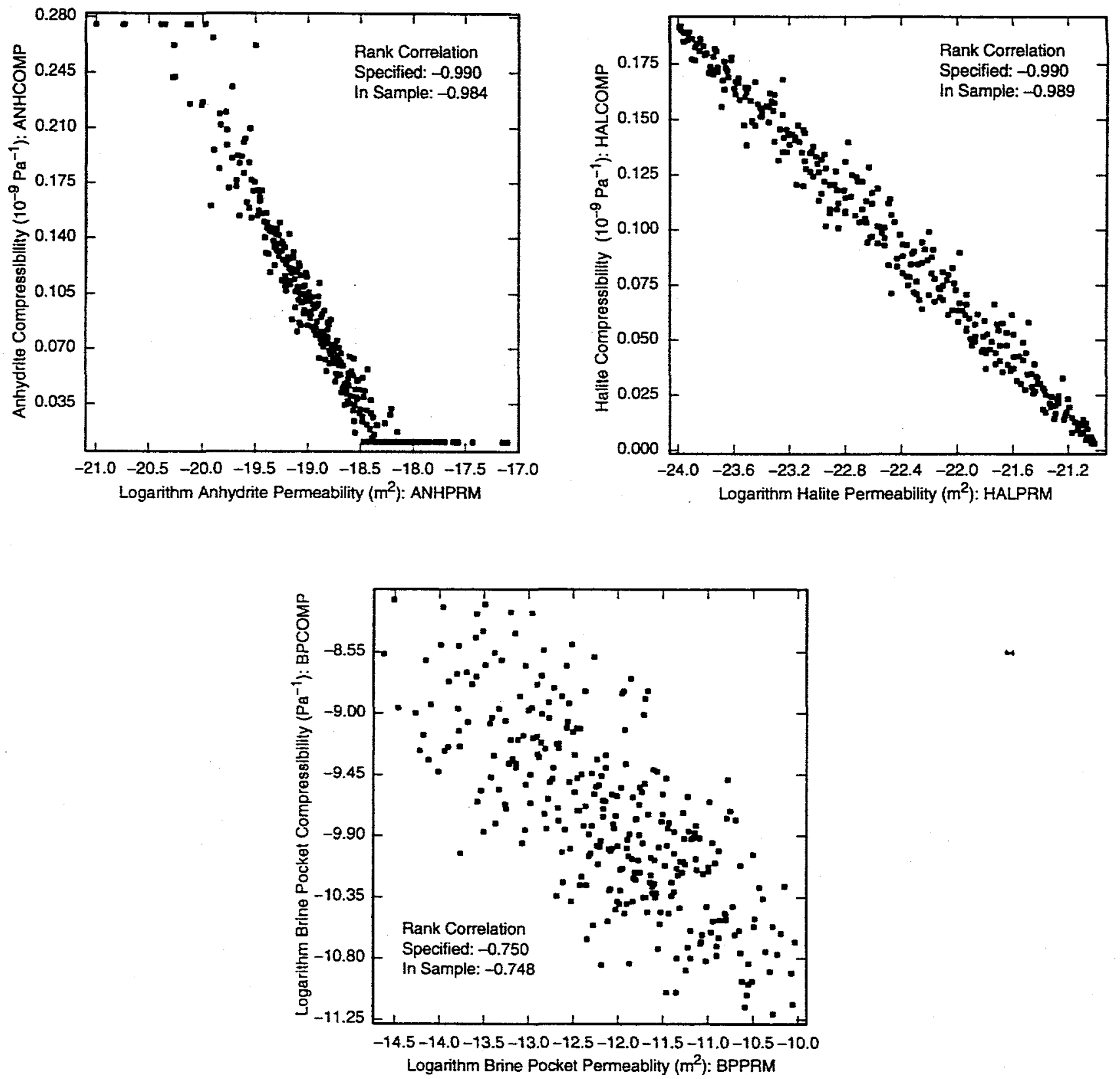

TRI-6342-5174-0dup

Fig. 3. Scatterplots illustrating correlations within the pairs (ANHCOMP, ANHPRM), (HALCOMP, HALPRM) and (BPCOMP, BPPRM). 
Table 1. Uncertain Variables Incorporated into 1996 WIPP PA (See App. PAR, Ref. 16 for additional information)

ANHBCEXP-Brooks-Corey pore distribution parameter for anhydrite (dimensionless). Used in BRAGFLO. Defines $\lambda$ in Eqs. (10) - (12) of Ref. 2 for regions 20, 21, 28 of Fig. 1 of Ref. 2 for use with Brooks-Corey model; defines $\lambda$ in $m=\lambda(1+\lambda)$ in Eqs. (19) - (21) of Ref. 2 for use with van Genuchten-Parker model in same regions. See $A N H B C V G P$. Distribution: Student's with 5 degrees of freedom. Range: 0.491 to 0.842 . Mean, Median: 0.644. Variable 25 in LHS. Additional information: Ref. 19; Ref. 20, Vol. 3, p. 2-54.

$A N H B C V G P$-Pointer variable for selection of relative permeability model for use in anhydrite. Used in BRAGFLO. See $A N H B C E X P$. Distribution: Discrete with $60 \% 0,40 \% 1$. Value of 0 implies Brooks-Corey model defined by Eqs. (10)-(12) of Ref. 2; value of 1 implies van Genuchten-Parker model defined by Eqs. (19)-(21) of Ref. 2. Variable 22 in LHS. Additional information: Ref. 19; Ref. 20, Vol. 3, p. A-149.

ANHCOMP-Bulk compressibility of anhydrite $\left(\mathrm{Pa}^{-1}\right)$. Used in BRAGFLO. Pore compressibility $\beta_{f}$ in Eq. (7) of Ref. 2 defined by $A N H C O M P$ divided by initial porosity (i.e., $\phi_{0}$ in Table 1 of Ref. 2 ) for use in regions 20,21, 28 of Fig. 1 of Ref. 2. Distribution: Student's with 3 degrees of freedom. Range: $1.09 \times 10^{-11}$ to 2.75 $\times 10^{-10} \mathrm{~Pa}^{-1}$. Mean, Median: $8.26 \times 10^{-11} \mathrm{~Pa}^{-1}$. Correlation: -0.99 rank correlation with ANHPRM. Variable 21 in LHS. Additional information: Refs. 21, 22.

ANHPRM-Logarithm of intrinsic anhydrite permeability $\left(\mathrm{m}^{2}\right)$. Used in BRAGFLO. Defines permeability tensors $K_{g}, K_{b}$ in Eqs. (2), (3) of Ref. 2 for regions 20, 21, 28 in Fig. 1 of Ref. 2. Specifically, the anhydrite is assumed to be isotropic, with result that $A N H P R M$ is the logarithm of the diagonal elements of $\mathrm{K}_{b}$ for the indicated regions and similarly defines the diagonal elements of $\boldsymbol{K}_{\boldsymbol{g}}$ after a correction is made for the Klinkenberg effect as shown in Eq. (30) of Ref. 2. Distribution: Student's with 5 degrees of freedom. Range: -21.0 to -17.1 (i.e., permeability range is $1 \times 10^{-21}$ to $1 \times 10^{-17.1} \mathrm{~m}^{2}$ ). Mean, Median: -18.9 . Correlation: -0.99 rank correlation with ANHCOMP. Variable 20 in LHS. Additional information: Refs. 19, 21, 22.

ANRBRSAT-Residual brine saturation in anhydrite (dimensionless). Used in BRAGFLO. Defines $S_{b r}$ in Eqs. (14) - (15) of Ref. 2 for use in regions 20, 21, 28 of Fig. 1 of Ref. 2. Distribution: Student's with 5 degrees of freedom. Range: $7.85 \times 10^{-3}$ to $1.74 \times 10^{-1}$. Mean, Median: $8.36 \times 10^{-2}$. Variable 23 in LHS. Additional information: Ref. 19; Ref. 20, Vol. 3, p. 2-52. 
Table 1. Uncertain Variables Incorporated into 1996 WIPP PA (Continued)

ANRGSSAT-Residual gas saturation in anhydrite (dimensionless). Used in BRAGFLO. Defines $S_{g r}$ in Eq. (15) of Ref. 2 for use in regions 20,21, 28 of Fig. 1 of Ref. 2. Distribution: Student's with 5 degrees of freedom. Range: $1.39 \times 10^{-2}$ to $1.79 \times 10^{-1}$. Mean, median: $7.71 \times 10^{-2}$. Variable 24 in LHS. Additional information: Ref. 19; Ref. 20, Vol. 3, p. 2-53.

BHPRM-Logarithm of intrinsic borehole permeability $\left(\mathrm{m}^{2}\right)$. Used in BRAGFLO. Defines permeability tensors $K_{g}, K_{b}$ in Eqs. (2), (3) of Ref. 2 for region 1 in Fig. 1 of Ref. 2 when borehole with properties similar to silty sand is present. Specifically, the borehole is assumed to be isotropic, with result that BHPRM is the logarithm of the diagonal elements of $K_{b}$ for the indicated region and similarly defines the diagonal elements of $\mathrm{K}_{\mathrm{g}}$ after a correction is made for the Klinkenberg effect as shown in Eq. (30) of Ref. 2. Distribution: Uniform. Range: -14 to -11 (i.e., permeability range is $1 \times 10^{-14}$ to $1 \times 10^{-11} \mathrm{~m}^{2}$ ). Mean, median: -12.5 . Variable 30 in LHS. Additional information: Ref. 23.

BPCOMP-Logarithm of bulk compressibility of brine pocket $\left(\mathrm{Pa}^{-1}\right)$. Used in BRAGFLO. Pore compressibility $\beta_{f}$ in Eq. (7) of Ref. 2 defined by $10 B P C O M P$ divided by initial porosity (i.e., $\phi_{0}$ in Table 1 of Ref. 2) for use in region 30 of Fig. 1 of Ref. 2. Distribution: Triangular. Range: -11.3 to -8.00 (i.e., bulk compressibility range is $1 \times 10^{-11.3}$ to $1 \times 10^{-8} \mathrm{~Pa}^{-1}$ ). Mean, mode: $-9.80,-10.0$. Correlation: -0.75 rank correlation with BPPRM. Variable 29 in LHS. Additional information: Ref. 24.

BPINTPRS-Initial pressure in brine pocket $(\mathrm{Pa})$. Used in BRAGFLO. Defines $p_{b}(x, y,-5)$ in Table 4 of Ref. 2 for region 30 in Fig. 1 of Ref. 2. Distribution: Triangular. Range: $1.11 \times 10^{7}$ to $1.70 \times 10^{7} \mathrm{~Pa}$. Mean, mode: $1.36 \times 10^{7} \mathrm{~Pa}, 1.27 \times 10^{7} \mathrm{~Pa}$. Variable 27 in LHS. Additional information: Ref. 25 ; Ref. 20, Vol. 3, Sect. 4.3.

BPPRM-Logarithm of intrinsic brine pocket permeability $\left(\mathrm{m}^{2}\right)$. Used in BRAGFLO. Defines permeability tensors $K_{g}, K_{b}$ in Eqs. (2), (3) of Ref. 2 for region 30 in Fig. 1 of Ref. 2 . Specifically, the brine pocket is assumed to be isotropic, with result that BPPRM is the logarithm of the diagonal elements of $K_{b}$ for the indicated region and similarly defines the diagonal elements of $K_{g}$ after a correction is made for the Klinkenberg effect as shown in Eq. (30) of Ref. 2. Distribution: Triangular. Range: -14.7 to -9.80 (i.e., permeability range is $1 \times 10^{-14.7}$ to $1 \times 10^{-9.80} \mathrm{~m}^{2}$ ). Mean, mode: $-12.1,-11.8$. Correlation: -0.75 with BPCOMP. Variable 28 in LHS. Additional information: Refs. 26, 27. 
Table 1. Uncertain Variables Incorporated into 1996 WIPP PA (Continued)

BPVOL-Pointer variable for selection of brine pocket volume. Used in BRAGFLO. Distribution: Discrete, with integer values $1,2, \ldots, 32$ equally likely. Originally intended to select from 32 equally-likely brine pocket maps obtained by assuming five regions beneath repository, with each region either containing or not containing pressurized brine. This produces 32 (i.e., $2^{5}$ ) possible brine pocket maps. This approach was abandoned when more information on brine pockets became available (Ref. 28) and the only role that $B P V O L$ now plays is to determine volume of brine $\left(\mathrm{m}^{3}\right)$ contained in the brine pocket. Specifically, the volumes are $32,000,64,000,96,000,128,000$ and $160,000 \mathrm{~m}^{3}$ if the original maps contained 0 or $1,2,3,4$ or 5 brine pockets, and the corresponding probabilities are $0.1875,0.3125,0.3125,0.15625$ and 0.03125 . The indicated volumes define $V_{b r}$ in Eq. (17) of Ref. 2 and thus define $\phi_{0}$ for region 30 in Fig. 1 of Ref. 2; in addition, the number of drilling intrusions $n D$ required to deplete the pressurized brine beneath the repository is defined by $n D=2 V_{b r m} / 32,000$ (i.e., $2,4,6,8$ or 10 intrusions depending on whether the associated brine volume is $32,000,64,000,96,000,128,000$ or $160,000 \mathrm{~m}^{3}$; see $n D$ in Table 5 of Ref. 11). For the presentation of sensitivity analysis results, $B P V O L$ is assigned the brine volumes that correspond to the sampled integer values. Variable 31 in LHS. Additional information: Refs. 28-30.

CFRCPOR-Culebra fracture (i.e., advective) porosity (dimensionless). Used in SECOTP2D. Defines $\phi$ in Eq. (13) of Ref. 6. Distribution: Loguniform Range: $1.00 \times 10^{-4}$ to $1.00 \times 10^{-2}$. Mean, median: $2.10 \times$ $10^{-3}, 1.00 \times 10^{-3}$. Variable 50 in LHS. Additional information: Refs. $31,32$.

CFRCSP-Culebra fracture spacing (m). Used in SECOTP2D. Equal to half the distance between fractures (i.e., the Culebra half matrix block length). Defines $B$ in Eq. (22) and Fig. 7 of Ref. 6. Distribution: Uniform. Range: 0.05 to $0.5 \mathrm{~m}$ Mean, median: $0.275 \mathrm{~m}, 0.275 \mathrm{~m}$. Variable 49 in LHS. Additional information: Refs. 33,34 .

CMKDAM3-Matrix distribution coefficient $\left(\mathrm{m}^{3} / \mathrm{kg}\right)$ for americium in +3 oxidation state. Used in SECOTP2D. Defines $K_{d k}$ in Eq. (19) of Ref. 6 for $\mathrm{Am}^{3+}$. Distribution: Uniform. Range: 0.02 to $0.5 \mathrm{~m}^{3} / \mathrm{kg}$. Mean, median: $0.26 \mathrm{~m}^{3} / \mathrm{kg}, 0.26 \mathrm{~m}^{3} / \mathrm{kg}$. Variable 57 in LHS. Additional information: Ref. 35 .

CMKDPU3-Same as CMKDAM3 but for plutonium in +3 oxidation state. Distribution: Uniform. Range: 0.02 to $0.5 \mathrm{~m}^{3} / \mathrm{kg}$. Mean, median: $0.26 \mathrm{~m}^{3} / \mathrm{kg}, 0.26 \mathrm{~m}^{3} / \mathrm{kg}$. Variable 54 in LHS.

CMKDPU4-Same as CMKDAM3 but for plutonium in +4 oxidation state. Distribution: Uniform Range: 0.9 to $20 \mathrm{~m}^{3} / \mathrm{kg}$. Mean, median: $10.0 \mathrm{~m}^{3} / \mathrm{kg}, 10.0 \mathrm{~m}^{3} / \mathrm{kg}$. Variable 55 in LHS. 
Table 1. Uncertain Variables Incorporated into 1996 WIPP PA (Continued)

CMKDTH4-Same as CMKDAM3 but for thorium in +4 oxidation state. Distribution: Uniform. Range: 0.9 to $20 \mathrm{~m}^{3} / \mathrm{kg}$. Mean, median: $10.0 \mathrm{~m}^{3} / \mathrm{kg}, 10.0 \mathrm{~m}^{3} / \mathrm{kg}$. Variable 56 in LHS.

CMKDU4-Same as CMKDAM3 but for uranium in +4 oxidation state. Distribution: Uniform. Range: 0.9 to $20 \mathrm{~m}^{3} / \mathrm{kg}$. Mean, median: $10.0 \mathrm{~m}^{3} / \mathrm{kg}, 10.0 \mathrm{~m}^{3} / \mathrm{kg}$. Variable 53 in LHS.

CMKDU6-Same as CMKDAM3 but for uranium in +6 oxidation state. Distribution: Uniform Range: $3.0 \times$ $10^{-5}$ to $3.0 \times 10^{-2} \mathrm{~m}^{3} / \mathrm{kg}$. Mean, median: $1.50 \times 10^{-2} \mathrm{~m}^{3 /} \mathrm{kg}, 1.50 \times 10^{-2} \mathrm{~m}^{3} / \mathrm{kg}$. Variable 52 in LHS.

CMTRXPOR-Culebra matrix (i.e., diffusive) porosity (dimensionless). Used in SECOFL2D and SECOTP2D. Defines $\phi^{\prime}$ in Eq. (18) of Ref. 6. Distribution: Piecewise uniform. Range: 0.01 to 0.25. Mean, median: $0.16,0.16$. Variable 51 in LHS. Additional information: Refs. 36, 37.

CTRAN-Pointer variable for selecting transmissivity field. Used in SECOFL2D. Distribution: Discrete, with integer values $1,2, \ldots, 100$ equally likely. Each integer value identifies one of 100 transmissivity fields constructed with GRASP_INV for use in analysis. Transmissivity fields define $T(x, y)$ in Eq. (7) of Ref. 6. Variable 35 in LHS. Additional information: Ref. 38; Ref. 20, Vol. 3, p. 2-91.

CTRANSFM-Multiplier on transmissivity field in presence of mining of potash reserves within the land withdrawal boundary (dimensionless). Used in SECOFL2D. Transmissivity field selected by CTRAN is multiplied by CTRANSFM to obtain values for $k_{1}(x, y)$ and $k_{2}(x, y)$ in Eqs. (8) and (9) of Ref. 6; defines SFM in Eqs (8) and (9) of Ref. 6 for mining. Distribution: Uniform. Range: 1 to 1000. Mean, median: 500.5, 500.5. Variable 34 in LHS. Additional information: Refs. $39-41$.

CULCLIM - Climate scale factor for Culebra flow (i.e., velocity) field (dimensionless). Used in SECOTP2D. Culebra flow field is multiplied by CULCLIM to obtain $v_{i}(x, y)$ in Eq. (11) of Ref. 6; defines SFC in Eq. (11) of Ref. 6. Distribution: Piecewise uniform Range: 1 to 2.25. Mean, median: $1.31,1.17$. Variable 48 in LHS. Additional information: Refs. 42, 43.

HALCOMP-Bulk compressibility of halite $\left(\mathrm{Pa}^{-1}\right)$. Used in BRAGFLO. Pore compressibility $\beta_{f}$ in Eq. (7) of Ref. 2 defined by $H A L C O M P$ divided by initial porosity (i.e., $\phi_{0}$ in Table 1 of Ref. 2 ) for use in region 19 of Fig. 1 of Ref. 2. Distribution: Uniform. Range: $2.94 \times 10^{-12}$ to $1.92 \times 10^{-10} \mathrm{~Pa}^{-1}$. Mean, median: $9.75 \times$ 10-11 $\mathrm{Pa}^{-1}, 9.75 \times 10^{-11} \mathrm{~Pa}^{-1}$. Correlation: -0.99 rank correlation with HALPRM. Variable 19 in LHS. Additional information: Ref. 44. 
Table 1. Uncertain Variables Incorporated into 1996 WIPP PA (Continued)

HALPOR-Halite porosity (dimensionless). Used in BRAGFLO. Defines $\phi_{0}$ in Eq. (7) of Ref. 2 for region 19 in Fig. 1 of Ref. 2. Distribution: Piecewise uniform. Range: $1.0 \times 10^{-3}$ to $3 \times 10^{-2}$. Mean, median: $1.28 \times$ $10^{-2}, 1.00 \times 10^{-2}$. Variable 17 in LHS. Additional information: Ref. 45; Ref. 20, Vol. 3, p. 2-41.

HALPRM - Logarithm of halite permeability $\left(\mathrm{m}^{2}\right)$. Used in BRAGFLO. Defines permeability tensors $\mathbf{K}_{\mathbf{g}}, \mathbf{K}_{b}$ in Eqs. (2), (3) of Ref. 2 for region 19 in Fig. 1 of Ref. 2. Specifically, the halite is assumed to be isotropic, with result that HALPRM is the logarithm of the diagonal elements of $\mathrm{K}_{b}$ for the indicated region and similarly defines the diagonal elements of $K_{g}$ after a correction is made for the Klinkenberg effect as shown in Eq. (30) of Ref. 2. Distribution: Uniform. Range: -24 to -21 (i.e., permeability range is $1 \times 10^{-24}$ to $1 \times 10^{-21} \mathrm{~m}^{2}$ ). Mean, median: $-22.5,-22.5$. Correlation: -0.99 rank correlation with HALCOMP. Variable 18 in LHS. Additional information: Refs. $46-48$.

SALPRES - Initial brine pressure, without the repository being present, at a reference point located in the center of the combined shafts at the elevation of the midpoint of MB $139(\mathrm{~Pa})$. Used in BRAGFLO. Defines $p_{b 0}$, which is used to define $p_{b}(x, y, 0)$ (Table 4 of Ref. 2). With respect to computational cells in Fig. 1 of Ref. 2, defines initial brine pressure at location of cell $(23,6)$. Distribution: Uniform. Range: $1.104 \times 10^{7}$ to $1.389 \times 10^{7} \mathrm{~Pa}$. Mean, median: $1.247 \times 10^{7} \mathrm{~Pa}, 1.247 \times 10^{7} \mathrm{~Pa}$. Variable 26 in LHS. Additional information: Ref. 49; Ref. 20, Vol. 3, p. 2-38.

SHBCEXP-Brooks-Corey pore distribution parameter for shaft (dimensionless). Used in BRAGFLO. Defines $\lambda$ in Eqs. (10) - (12) of Ref. 2 for regions 3-11 in Fig. 1 of Ref. 2. Distribution: Piecewise uniform. Range: 0.11 to 8.10 . Mean, median: 2.52, 0.94. Variable 16 in LHS. Additional information: Refs. $50-52$. SHPRMASP-Logarithm of intrinsic permeability $\left(\mathrm{m}^{2}\right)$ of asphalt component of shaft seal $\left(\mathrm{m}^{2}\right)$. Used in BRAGFLO. Permeability tensors $K_{g}, K_{b}$ in Eqs. (2), (3) of Ref. 2 for region 5 in Fig. 1 of Ref. 2 are functions of asphalt permeability (i.e., $k_{s}=10 x, x=S H P R M A S P$, in Eq. (35) of Ref. 2), halite permeability (i.e., $k_{\text {out }}=*$ $10^{x}, x=H A L P R M$, in Eq. (36) of Ref. 2, and shaft DRZ permeability (i.e., $k_{i n}=10^{x}, x=S H P R M D R Z$, in Eq. (36) of Ref. 2), with diagonal elements of $K_{b}$ defined by $k_{e}$ in Eq. (35) of Ref. 2 and the diagonal elements of $K_{g}$ defined similarly after a correction is made for the Klinkenberg effect as shown in Eq. (30) of Ref. 2. Distribution: Triangular. Range: -21 to -18 (i.e., permeability range is $1 \times 10^{-21}$ to $1 \times 10^{-18} \mathrm{~m}^{2}$ ). Mean, mode: $-19.7,-20.0$. Variable 11 in LHS. Additional information: Refs. 50, $51,53$. 
Table 1. Uncertain Variables incorporated into 1996 WIPP PA (Continued)

SHPRMCLY-Logarithm of intrinsic permeability $\left(\mathrm{m}^{2}\right)$ for clay components of shaft. Used in BRAGFLO. Defines permeability tensors $K_{g}, K_{b}$ in Eqs. (2), (3) of Ref. 2 for regions 4, 10 in Fig. 1 of Ref. 2; specifically, the clay component is assumed to be isotropic, with result that SHPRMCLY is the logarithm of the diagonal elements of $K_{b}$ for the indicated regions and the diagonal elements of $K_{g}$ are defined similarly after a correction is made for Klinkenberg effect as shown in Eq. (30) of Ref. 2. Plays same role in definition of $\mathbf{K}_{g}$, $K_{b}$ for regions 8, 9 in Fig. 1 of Ref. 2 as SHPRMASP does in the definition of $K_{g}, K_{b}$ for region 5 in Fig. 1 of Ref. 2, with result that $\mathrm{K}_{\mathrm{g}}, \mathrm{K}_{b}$ are functions of SHPRMCLY, HALPRM and SHPRMDRZ. Distribution: Triangular. Range: -21 to -17.3 (i.e., permeability range is $1 \times 10^{-21}$ to $1 \times 10^{-17.3} \mathrm{~m}^{2}$ ). Mean, mode: $-18.9,-18.3$. Variable 9 in LHS. Additional information: Refs. $50,51,53$.

SHPRMCON -Same as SHPRMCLY (as used for regions 4, 10 in Fig. 1 of Ref. 2) but for concrete component of shaft seal (i.e., region 6 in Fig. 1 of Ref. 2) for 0 to 400 yr. Distribution: Triangular. Range: -17.0 to -14.0 (i.e., permeability range is $1 \times 10^{-17}$ to $1 \times 10^{-14} \mathrm{~m}^{2}$ ). Mean, mode: $-15.3,-15.0$. Variable 10 in LHS. Additional information: Refs. 50,51, 53.

SHPRMDRZ-Logarithm of intrinsic permeability $\left(\mathrm{m}^{2}\right)$ of DRZ surrounding shaft. Used in BRAGFLO. Defines $k_{i n}$ in Eq. (36) of Ref. 2. Used in definition of effective permeability for shaft in regions $5,8,7$ and 9 of Fig. 1 of Ref. 2. See SHPRMASP, SHPRMCLY, SHPRMHAL. Distribution: Triangular. Range: -17.0 to -14.0 (i.e., permeability range is $1 \times 10^{-17}$ to $1 \times 10^{-14} \mathrm{~m}^{2}$ ). Mean, mode: $-15.3,-15.0$. Variable $12 \mathrm{in}$ LHS. Additional information: Refs. 50, 51, 54 .

SHPRMHAL - Pointer variable (dimensionless) used to select intrinsic permeability in crushed salt component of shaft seal at different times. Used in BRAGFLO. Distribution: Uniform. Range: 0 to 1 . Mean, mode: $0.5,0.5$. A distribution of permeability $\left(\mathrm{m}^{2}\right)$ in the crushed salt component of the shaft seal (i.e., region 7 in Fig. 1 of Ref. 2) is defined for each of the following time intervals: [0,10 yr], [10, 25 yr], [25, $50 \mathrm{yr}],[50,100$ yr], $[100,200 \mathrm{yr}],[200,10,000 \mathrm{yr}]$ (see Table 2, Ref. 50). SHPRMHAL is used to select a permeability value from the cumulative distribution function for permeability for each of the preceding time intervals with result that a rank correlation of 1 exists between the permeabilities used for the individual time intervals. Once selected, crushed salt permeabilities are used to define $K_{g}, K_{b}$ in Eqs. (2), (3) of Ref. 2. For region 7 (Fig. 1 of Ref. 2) in the same manner as SHPRMASP is used to define $K_{g}, K_{b}$ for region 5 (Fig. 1 of Ref. 2). Variable 13 in LHS. Additional information: Refs. 50, 51, 55 . 
Table 1. Uncertain Variables Incorporated into 1996 WIPP PA (Continued)

SHRBRSAT - Residual brine saturation in shaft (dimensionless). Used in BRAGFLO. Defines $S_{b r}$ in Eqs. (24) - (25) of Ref. 2 for regions 3-11 in Fig. 1 of Ref. 2. Distribution: Uniform. Range: 0 to 0.4. Mean, median: $0.2,0.2$. Variable 15 in LHS. Additional information: Refs. $50,51$.

SHRGSSAT-Residual gas saturation in shaft (dimensionless). Used in BRAGFLO. Defines $S_{g r}$ in Eq. (25) of Ref. 2 for regions 3-11 in Fig. 1 of Ref. 2. Distribution: Uniform. Range: 0 to 0.4. Mean, median: $0.2,0.2$. Variable 14 in LHS. Additional information: Refs. 50, 51, 56.

WASTWICK-Increase in brine saturation of waste due to capillary forces (dimensionless). Used in BRAGFLO. Defines $S_{\text {wick }}$ in Eq. (72) of Ref. 2 for regions 23, 24 in Fig. 1 of Ref. 2. Distribution: Uniform. Range: 0 to 1 . Mean, median: $0.5,0.5$. Variable 8 in LHS.

WFBETCEL-Scale factor used in definition of stoichiometric coefficient for microbial gas generation : (dimensionless). Used in BRAGFLO. Defines $\beta$ in Eq. (71) of Ref. 2 for regions 23, 24 in Fig. 1 of Ref. 2. Distribution: Uniform. Range: 0 to 1. Mean, median: $0.5,0.5$. Variable 5 in LHS. Additional information: Refs. 57, 58.

WGRCOR - Corrosion rate for steel under inundated conditions in the absence of $\mathrm{CO}_{2}(\mathrm{~m} / \mathrm{s})$. Used in BRAGFLO. Defines $R_{c i}$ in Eq. (50) of Ref. 2 for regions 23, 24 in Fig. 1 of Ref. 2. Distribution: Uniform. Range: 0 to $1.58 \times 10^{-14} \mathrm{~m} / \mathrm{s}$. Mean, median: $7.94 \times 10^{-15} \mathrm{~m} / \mathrm{s}, 7.94 \times 10^{-15} \mathrm{~m} / \mathrm{s}$. Variable $1 \mathrm{in} \mathrm{LHS}$. Additional information: Ref. 57.

WGRMICH-Microbial degradation rate for cellulose under humid conditions (mol/kg•s). Used in BRAGFLO. Defines $R_{m h}$ in Eq. (52) of Ref. 2 for regions 23, 24 in Fig. 1 of Ref. 2. Distribution: Uniform. Range: 0 to $1.27 \times 10^{-9} \mathrm{~mol} / \mathrm{kg} \bullet \mathrm{s}$. Mean, median: $6.34 \times 10^{-10} \mathrm{~mol} / \mathrm{kg} \bullet \mathrm{s}, 6.34 \times 10^{-10} \mathrm{~mol} / \mathrm{kg} \bullet \mathrm{s}$. Variable 4 in LHS. Additional information: Ref. 57.

WGRMICI-Microbial degradation rate for cellulose under inundated conditions (mol/kg•s). Used in BRAGFLO. Defines $R_{m i}$ in Eq. (52) of Ref. 2 for regions 23, 24 in Fig. 1 of Ref. 2. Distribution: Uniform. Range: $3.17 \times 10^{-10}$ to $9.51 \times 10^{-9} \mathrm{~mol} / \mathrm{kg} \bullet$. Mean, median: $4.92 \times 10^{-9} \mathrm{~mol} / \mathrm{kg} \bullet \mathrm{s}, 4.92 \times 10^{-9} \mathrm{~mol} / \mathrm{kg} \bullet \mathrm{s}$. Variable 3 in LHS. Additional information: Ref. 57. 
Table 1. Uncertain Variables Incorporated into 1996 WIPP PA (Continued)

WMICDFLG Pointer variable for microbial degradation of cellulose. Used in BRAGFLO. Distribution: Discrete, with $50 \% 0,25 \% 1,25 \% 2$. WMICDFLG $=0,1,2$ implies no microbial degradation of cellulose, microbial degradation of only cellulose, microbial degradation of cellulose, plastic and rubber. Variable 2 in LHS. Additional information: Ref. 59.

WPRTDIAM-Waste particle diameter (m). Used in CUTTINGS_S. Defines $d$ in Eqs. (40) and (41) of Ref. 3. Distribution: Loguniform. Range: $4.0 \times 10^{-5}$ to $2.0 \times 10^{-1} \mathrm{~m}$. Mean, median: $2.35 \times 10^{-2} \mathrm{~m}, 2.80 \times$ $10^{-2} \mathrm{~m}$. Variable 32 in LHS. Additional information: Refs. 60, 61.

WOXSTAT-Pointer variable for elemental oxidation states (dimensionless). Solubilities obtained with WOXSTAT used in NUTS, PANEL (see Eqs. (6)-(9) and Table 1) of Ref. 5; retardations obtained with WOXSTAT used in SECOTP2D (see Eq. (19) of Ref. 6). Distribution: Uniform. Range: 0 to 1. Mean, median: $0.5,0.5$. Reset to WOXSTAT $=0,1$ for WOXSTAT $\leq 0.5,0.5<$ WOXSTAT $\leq 1$. WOXSTAT $=0$ implies use of CMKDPU3, CMKDU4, WSOLPU3C, WSOLPUS, WSOLU4S; WOXSTAT = 1 implies use of CMKDPU4, CMKDU6, WSOLPU4C, WSOLPU4S, WSOLU6C, WSOLU6S. Variable 47 in LHS. Additional information. Refs. $62,63$.

WPHUMOX3-Ratio of concentration of actinides attached to humic colloids to dissolved concentration of actinides for oxidation state III in Castile brine (dimensionless). See $S F_{H u m}(B r, O x, E l)$ in Table 1 of Ref. 5. Distribution: Piecewise uniform. Range: 0.065 to 1.60 . Mean, median: $1.10,1.37$. Variable 46 in LHS. Additional information: Refs. $64-66$.

WRBRNSAT - Residual brine saturation in waste (dimensionless). Used in BRAGFLO. Defines $S_{b r}$ in Eqs. (14) - (15) of Ref. 2 for use in regions 23, 24 in Fig. 1 of Ref. 2. Also used in BRAGFLO_DBR; see Sect. 4 of Ref. 4. Distribution: Uniform. Range: 0 to 0.552 . Mean, median: $0.276,0.276$. Variable 7 in LHS. Additional information: Ref. 67.

WRGSSAT-Residual gas saturation in waste (dimensionless). Used in BRAGFLO. Defines $S_{g r}$ in Eq. (15) of Ref. 2 for use in regions 23, 24 in Fig. 1 of Ref. 2. Also used in BRAGFLO_DBR; see Sect. 4 of Ref. 4. Distribution: Uniform. Range: 0 to 0.15 . Mean, median: $0.075,0.075$. Variable 6 in LHS. Additional information: Ref. 68. 
Table 1. Uncertain Variables Incorporated into 1996 WIPP PA (Continued)

WSOLAM $3 C$ - Logarithm of scale factor used to define solubility in Castile brine of americium in oxidation state III (dimensionless). Solubility calculated from WSOLAM3C used in NUTS, PANEL. Defines $U F(B r$, $O x, E l$ in Table 1 of Ref. 5, which is a multiplier on solubility prediction with FMT (Ref. 69). Distribution: Piecewise uniform. Range: -2.00 to 1.40. Mean, median: $0.18,-0.09$. Variable 37 in LHS. Additional information: Refs. 63, $70-72$.

WSOLAM3S-Same as WSOLAM3C but for Salado brine. Variable 36 in LHS. Note: WSOLAM3C, WSOLAM3S, WSOLPU3C, WSOLPU3S, WSOLPU4C, WSOLPU4S, WSOLTH4S, WSOLU4S, WSOLU6C, WSOLU6S have same distribution (see WSOLAM3C) but are sampled independently.

WSOLPU3C-Same as WSOLAM3C but for plutonium. Variable 39 in LHS.

WSOLPU3S-Same as WSOLAM3C but plutonium in Salado brine. Variable 38 in LHS.

WSOLPU4C - Same as WSOLAM3C but for plutonium in oxidation state IV. Variable 41 in LHS.

WSOLPO4S Same as WSOLAM3C but for plutonium in oxidation state $\mathrm{IV}$ in Salado brine. Variable 40 in LHS.

WSOLTH4S-Same as WSOLAM3C but for thorium in oxidation state IV in Salado brine. Variable 45 in LHS.

WSOLU4S-Same as WSOLAM3C but for uranium in oxidation state IV in Salado brine. Variable 42 in LHS.

WSOLU6C - Same as WSOLAM3C but for uranium in oxidation state VI. Variable 44 in LHS.

WSOLU6S-Same as WSOLAM3C but for uranium in oxidation state VI in Salado brine. Variable 43 in LHS.

WTAUFAIL_Shear strength of waste (Pa). Used in CUTTINGS_S. Defines $\tau(R, 1)$ in Eq. (13) of Ref. 3.

Distribution: Uniform Range: 0.05 to $10 \mathrm{~Pa}$. Mean, median: $5.03 \mathrm{~Pa}, 5.03 \mathrm{~Pa}$. Variable 33 in LHS. Additional information: Ref. 73. 
Table 2. Example Rank Correlations in Replicate 1

\begin{tabular}{lcccccccc}
\hline WGRCOR & 1.0000 & & & & & & & \\
WMICDFLG & 0.0198 & 1.0000 & & & & & & \\
HALCOMP & 0.0011 & 0.0235 & 1.0000 & & & & & \\
HALPRM & -0.0068 & -0.0212 & -0.9879 & 1.0000 & & & & \\
ANHCOMP & 0.0080 & 0.0336 & -0.0123 & -0.0025 & 1.0000 & & & \\
ANHPRM & 0.0049 & -0.0183 & 0.0037 & 0.0113 & -0.9827 & 1.0000 & & \\
BPCOMP & 0.0242 & 0.1071 & -0.0121 & 0.0057 & -0.0184 & 0.0078 & 1.0000 & $\cdot$ \\
BPPRM & -0.0514 & -0.0342 & 0.0035 & 0.0097 & 0.0283 & -0.0202 & -0.7401 & 1.0000 \\
& WGRCOR & WMICDFLG & HALCOMP & HALPRM & ANHCOMP & ANHPRM & BPCOMP & BPPRM
\end{tabular}




\section{Correlation Control (Adapted from Sect. 3.2 of Helton 1993)}

Control of correlation within a sample can be very important. If two or more variables are correlated, then it is necessary that the appropriate correlation structure be incorporated into the sample if meaningful results are to be obtained in subsequent uncertainty/sensitivity studies. On the other hand, it is equally important that variables do not appear to be correlated when they are really independent.

It is often difficult to induce a desired correlation structure on a sample. Indeed, most multivariate distributions are incompatible with the majority of correlation patterns that might be proposed for them. Thus, it is fairly common to encounter analysis situations where the proposed variable distributions and the suggested correlations between the variables are inconsistent; that is, it is not possible to have both the desired variable distributions and the requested correlations between the variables.

In response to this situation, Iman and Conover (1982) have proposed a method of controlling the correlation structure in random and Latin hypercube samples that is based on rank correlation (i.e., on rank-transformed variables) rather than sample correlation (i.e., on the original untransformed data). With their technique, it is possible to induce any desired rank-correlation structure onto the sample. This technique has a number of desirable properties: (i) It is distribution free. That is, it may be used with equal facility on all types of distribution functions. (ii) It is sitmple. No unusual mathematical techniques are required to implement the method. (iii) It can be applied to any sampling scheme for which correlated input variables can logically be considered, while preserving the intent of the sampling scheme. That is, the same numbers originally selected as imput values are retained; only their pairing is affected to achieve the desired rank correlations. This means that in Latin hypercube sampling the integrity of the intervals is maintained. If some other structure is used for selection of values, that same structure is retained. (iv) The marginal distributions remain intact.

For many, if not most, uncertainty/sensitivity analysis problems, rank-correlation is probably a more natural measure of congruent variable behavior than is the more traditional sample correlation. What is known in most situations is some idea of the extent to which variables tend to move up or down together; more detailed assessments of variable linkage are usually not available. It is precisely this level of knowledge that rank correlation captures.

The following discussion provides an overview of the Iman/Conover procedure for inducing a desired rank correlation structure on either a random or a Latin hypercube sample. A more detailed discussion of the procedure is given in the original article. The procedure begins with a sample of size $m$ from the $n$ input variables under consideration. This sample can be represented by the $m \times n$ matrix 


$$
\mathbf{X}=\left[\begin{array}{cccc}
x_{11} & x_{12} & \cdots & x_{1 n} \\
x_{21} & x_{22} & \cdots & x_{2 n} \\
\vdots & \vdots & & \vdots \\
x_{m 1} & x_{m 2} & \cdots & x_{m n}
\end{array}\right]
$$

where $x_{i j}$ is the value for variable $j$ in sample element $i$. Thus, the rows of $\mathbf{X}$ correspond to sample elements, and the columns of $\mathbf{X}$ contain the sampled values for individual variables.

The procedure is based on rearranging the values in the individual columns of $X$ so that a desired rank correlation structure results between the individual variables. For convenience, let the desired correlation structure be represented by the $n \times n$ matrix

$$
\mathrm{C}=\left[\begin{array}{cccc}
c_{11} & c_{12} & \cdots & c_{l n} \\
c_{21} & c_{22} & \cdots & c_{2 n} \\
\vdots & \vdots & & \vdots \\
c_{n 1} & c_{n 2} & \cdots & c_{n n}
\end{array}\right]
$$

where $c_{k l}$ is the desired rank correlation between variables $x_{k}$ and $x_{l}$.

Althorgh the procedure is based on rearranging the values in the individual columns of $\mathbf{X}$ to obtain a new matrix $\mathbf{X}^{*}$ that has a rank correlation structure close to that described by $C$, it is not possible to work directly with $\mathbf{X}$. Rather, it is necessary to define a new matrix

$$
\mathbf{S}=\left[\begin{array}{cccc}
s_{11} & s_{12} & \cdots & s_{1 n} \\
s_{21} & s_{22} & \cdots & s_{2 n} \\
\vdots & \vdots & & \vdots \\
s_{m 1} & s_{m 2} & \cdots & s_{m n}
\end{array}\right]
$$

that has the same dimensions as $\mathbf{X}$, but is otherwise independent of $\mathbf{X}$. Each colurm of $\mathbf{S}$ contains a random permutation of the $m$ van der Waerden scores (Conover 1980) $\Phi^{-1}(i / m+1), i=1,2, \ldots, m$, where $\Phi^{-1}$ is the inverse of the standard normal distribution. The matrix $\mathbf{S}$ is then rearranged to obtain the correlation structure defined by C. This rearrangement is based on the Cholesky factorization (Golub and van Loan 1983) of C. That is, a lower triangular matrix $\mathrm{P}$ is constructed such that

$$
\mathbf{C}=\mathbf{P P}^{T} \text {. }
$$

This construction is possible because $C$ is a symmetric, positive-definite matrix (Golub and van Loan 1983, p. 88).

If the correlation matrix associated with $S$ is the $n \times n$ identity matrix (i.e., if the correlations between the values in different columns of $\mathbf{S}$ are zero), then the correlation matrix for 
is $\mathbf{C}$ (Anderson 1984, p. 25). At this point, the success of the procedure depends on the following two conditions: (1) that the correlation matrix associated with $\mathrm{S}$ be close to the $n \times n$ identity matrix; and (2) that the correlation matrix for $\mathbf{S}^{*}$ be approximately equal to the rank correlation matrix for $\mathbf{S}^{\star}$. If these two conditions hold, then the desired matrix $\mathbf{X}^{\star}$ can be obtained by simply rearranging the values in the individual columns of $\mathbf{X}$ in the same rank order as the values in the individual columns of $\mathbf{S}^{*}$. This is the first time that the variable values contained in $X$ enter into the correlation process. When $X^{*}$ is constructed in this manner, it will have the same rank correlation matrix as $S^{\star}$. Thus, the rank correlation matrix for $X^{\star}$ will approximate $\mathbf{C}$ to the same extent that the rank correlation matrix for $S^{\star}$ does.

The condition that the comelation matrix associated with $\mathbf{S}$ be close to the identity matrix is now considered. For convenience, the correlation matrix for $\mathbf{S}$ will be represented by $\mathbf{E}$. Unfortunately, $\mathbf{E}$ will not always be the identity matrix. However, it is possible to make a correction for this. The starting point for this correction is the Cholesky factorization for $\mathbf{E}$ :

$$
\mathbf{E}=\mathbf{Q Q}^{T}
$$

This factorization exists because $E$ is a symmetric, positive-definite matrix. The matrix $S^{\star}$ defined by

$$
\mathbf{S}^{*}=\mathbf{S}\left(\mathbf{Q}^{-1}\right)^{T} \mathbf{P} T
$$

has $\mathbf{C}$ as its correlation matrix. In essence, multiplication of $\mathbf{S}$ by $\left(\mathbf{Q}^{-1}\right)^{T}$ transforms $\mathbf{S}$ into a matrix whose associated correlation matrix is the $n \times n$ identity matrix; then, multiplication by $\mathbf{P}^{T}$ produces a matrix whose associated correlation matrix is $C$. As it is not possible to be sure that $\mathbf{E}$ will be an identity matrix, the matrix $\mathbf{S *}$ used in the procedure to produce correlated input should be defined in the corrected form shown in Eq. (10) rather than in the uncorrected form shown in Eq. (8).

The condition that the correlation matrix for $S^{*}$ be approximately equal to the rank correlation matrix for $S^{\star}$ depends on the choice of the scores used in the definition of $\mathbf{S}$. On the basis of empirical investigations, Iman and Conover (1982) found that van der Waerden scores provided an effective means of defining $\mathbf{S}$, and these scores are incorporated into the rank correlation procedure in the widely used LHS program (Iman and Shortencarier 1984). Other possibilities for defining these scores exist, but have not been extensively investigated. The user should examine the rank correlation matrix associated with $\mathbf{S}^{*}$ to ensure that it is close to the target correlation matrix $\mathbf{C}$. If this is not the case, the construction procedure used to obtain $S^{*}$ can be repeated until a suitable approximation to $C$ is obtained. Results given in Iman and Conover (1982) indicate that the use of van der Waerden scores leads to rank correlation matrices for $S^{\star}$ that are close to the target matrix $\mathbf{C}$. 
Additional information on the Iman/Conover (i.e., restricted pairing) technique to induce a desired rankcorrelation structure is given in the original article. The results of various rank-correlation assurmptions are illustrated in Iman and Davenport (1982). The LHS program generates both random and Latin hypercube samples with user-specified rank correlations between variables.

The numerical implementation of the sensitivity analysis techniques used in this report involves the investigation of the effects of elements of $\mathbf{x}_{s u}$ on single elements of $\mathbf{y}\left(\mathbf{x}_{s u}\right)$. For notational convenience in the description of these techniques, the mapping in Eq. (15) will be represented by

$$
\left[\mathrm{x}_{k}, y_{k}\right], k=1,2, \ldots, n L H S \text {, }
$$

where

$$
x_{k}=\left[x_{k 1}, x_{k 2} \ldots, x_{k, n V}\right]
$$

and $y_{k}$ corresponds to one element of $\mathbf{y}\left(\mathbf{x}_{k}\right)$. The vector $\mathbf{x}_{k}$ corresponds to the vector $\mathbf{x}_{s u, k}$ in Eq. (15) with the subscript su dropped to produce a less cumbersome notation.

To make efficient use of all available information, most of the sensitivity analysis results contained in this report are based on a pooling of the results obtained for the three replicated LHSs (i.e., R1, R2, R3) discussed in Sect. 11. Thus, the mapping in use is actually of the form

$$
\left[\mathrm{x}_{k}, y_{k}\right], k=1,2, \ldots, 3 \cdot n L H S,
$$

where $k=1,2, \ldots, 100$ corresponds to results from replicate $\mathrm{R} 1, k=101,102, \ldots, 200$ corresponds to results from replicate $\mathrm{R} 2$, and $k=201,202, \ldots, 300$ corresponds to results from replicate $\mathrm{R} 3$. The discussions in this section will refer to the simpler mapping in Eq. (16) rather than the mapping in Eq. (18), although the numerical examples will actually be generated with the mapping in Eq. (18).

\subsection{Scatterplots}

The generation of scatterplots is undoubtedly the simplest sensitivity analysis technique and only involves plotting the points

$$
\left(x_{k j}, y_{k}\right), k=1,2, \ldots, n L H S \text {, }
$$

for each element $x_{j}$ of $\mathrm{x}$ for $j=1,2, \ldots, n V$ (see Eq. (17)). This produces $n V$ scatterplots that can then be examined for relationships between $y$ and the elements of $\mathbf{x}$ (i.e., the $x_{j}$ ). As an example, the scatterplot in Fig. 3 shows a nonlinear but monotonic relationship between borehole permeability (BHPRM) and cumulative brine flow down an 
intruding borehole, with no brine flow taking place for small values of $B H P R M$ and brine flow increasing rapidly for larger values of BHPRM (see Sect. 2, Helton et al. 1998d, for additional discussion). As another example, the scatterplot in Fig. 4 shows a complex relationship between BHPRM and repository pressure that is both nonlinear and nonmonotonic, with repository pressure decreasing as BHPRM increases and then undergoing a sudden jump at $B H P R M \doteq-11.7$ (i.e., at a permeability of $10^{-11.7} \mathrm{~m}^{2} \doteq 2 \times 10^{-12} \mathrm{~m}^{2}$ ) (see Sect. 8.3, Helton et al. 1998d, for additional discussion). In contrast to the well-defined patterns in Figs. 3 and 4, the individual points will be randomly spread over the plot when there is no relationship between $y$ and a particular $x_{j}$.

Sometimes scatterplots alone will completely reveal the relationships between model input (i.e., elements of $\mathbf{x}$ ) and model predictions (i.e., $y$ ). This is often the case when only one or two inputs dominate the outcome of the analysis. Further, scatterplots often reveal nonlinear relationships, thresholds and variable interactions that facilitate the understanding of model behavior and the planning of more sophisticated sensitivity studies. Iman and Helton (1988) provide an example where the examination of scatterplots revealed a rather complex pattern of variable interactions. The examination of scatterplots is always a good starting point in a sensitivity study. The examination of such plots when Latin hypercube sampling is used can be particularly revealing due to the full stratification over the range of each input variable.

\subsection{Regression Analysis}

A more formal investigation of the mapping in Eq. (16) can be based on regression analysis. In this approach, a model of the form

$$
y=b_{0}+\sum_{j=1}^{n} b_{j} x_{j}
$$

is developed from the mapping between analysis inputs and analysis results shown in Eq. (16), where the $x_{j}$ are the input variables under consideration and the $b_{j}$ are coefficients that must be determined. The coefficients $b_{j}$ and other aspects of the construction of the regression model in Eq. (20) can be used to indicate the importance of the individual variables $x_{j}$ with respect to the uncertainty in $y$.

The construction of the regression model in Eq. (20) is considered first. To keep the notation from becoming unwieldy, $n$ will be used to denote the number of independent variables under consideration (i.e., $n=n V$ as used in Eq. (17)) and $m$ will be used to denote the number of observations under consideration (i.e., $m=n L H S$ or $3 \bullet n L H S$ as used in Eqs. (16) or (18)). As shown in Eq. (16), there exists a sequence $y_{k}, k=1, \ldots, m$, of values for the output variable. When expressed in the form of the model in Eq. (20), each $y_{k}$ becomes 


$$
y_{k}=b_{0}+\sum_{j=1}^{n} b_{j} x_{k j}+\varepsilon_{k}, \quad k=1, \ldots, m,
$$

where the error terms $\varepsilon_{k}, k=1, \ldots, m$, equal the difference between the observed value $y_{k}$ and the corresponding predicted value $\hat{y}_{k}$ defined by Eq. (20). At this point, the $b_{j}$ are still unknown. What is desired is to determine the $b_{j}$ in some suitable manner. The method of least squares is widely used and will be employed here (Harter 1983, Eisenhart 1964). As a result of its extensive use, there exist a number of excellent textbooks on least squares regression analysis (Myers 1986, Weisberg 1985, Seber 1977, Draper and Smith 1981, Daniel et al. 1980, Neter and Wasserman 1974). The purpose of the following discussion is to present just enough information to be able to describe some of the applications of regression-based techniques in sensitivity analysis. The indicated textbooks, as well as many others, provide far more information on regression analysis than can be presented here.

To determine the $b_{j}$, it is convenient to use the following matrix representation for the equalities in Eq. (22):

$$
\mathbf{y}=\mathbf{X b}+\varepsilon
$$

where

$$
\mathbf{y}=\left[\begin{array}{c}
y_{1} \\
\vdots \\
y_{m}
\end{array}\right], \quad \mathbf{X}=\left[\begin{array}{cccc}
1 & x_{11} & \cdots & x_{1 n} \\
\vdots & \vdots & & \vdots \\
1 & x_{m 1} & \cdots & x_{m n}
\end{array}\right], \quad \mathbf{b}=\left[\begin{array}{c}
b_{0} \\
\vdots \\
b_{n}
\end{array}\right] \text { and } \quad \varepsilon=\left[\begin{array}{c}
\varepsilon_{1} \\
\vdots \\
\varepsilon_{m}
\end{array}\right]
$$

In the least squares approach, the intent is to determine the $b_{j}$ such that the sum

$$
S(\mathbf{b})=\sum_{k=1}^{m}\left(y_{k}-b_{0}-\sum_{j=1}^{n} b_{j} x_{k j}\right)^{2}=(\mathbf{y}-\mathbf{X b})^{T}(\mathbf{y}-\mathbf{X b})
$$

is a minimum. Put another way, the $b_{j}$ are determined such that the sum $\sum_{k} \varepsilon_{k}^{2}$ involving the error terms is a minimum. The determination of the $b_{j}$ in the least squares approach is just an exercise in calculus and is based on consideration of the first derivatives of $S(\mathbf{b})$ with respect to the individual $b_{j}$ (Draper and Smith 1981).

This derivation leads to the following matrix equation that defines the coefficient vector $b$ for which the sum $S(b)$ given in Eq. (23) is a minimum:

$$
\mathbf{X}^{T} \mathbf{X b}=\mathbf{X}^{T} \mathbf{Y}
$$

For the analysis to produce a unique value for the coefficient vector $\mathbf{b}$, it is necessary that the matrix $\mathbf{X}^{T} \mathbf{X}$ be invertible. Then, $b$ is given by 


$$
\mathbf{b}=\left(\mathbf{X}^{T} \mathbf{X}\right)^{-1} \mathbf{X}^{T} \mathbf{y}
$$

The matrix $\mathbf{X}^{T} \mathbf{X}$ will always be invertible when the columns of $\mathbf{X}$ are linearly independent. This usually is the case in a sampling-based study in which the number of sample elements (i.e., $m$ ) exceeds the number of independent variables (i.e., $n$ ).

The following identity holds for the least squares regression model and plays an important role in assessing the adequacy of such models:

$$
\sum_{k=1}^{m}\left(y_{k}-\bar{y}\right)^{2}=\sum_{k=1}^{m}\left(\hat{y}_{k}-\bar{y}\right)^{2}+\sum_{k=1}^{m}\left(\hat{y}_{k}-y_{k}\right)^{2},
$$

where $\hat{y}_{k}$ denotes the estimate of $y_{k}$ obtained from the regression model and $\bar{y}$ is the mean of the $y_{k}$ (Draper and Smith, 1981). Since

$$
\sum_{k=1}^{m}\left(\hat{y}_{k}-y_{k}\right)^{2}
$$

provides a measure of variability about the regression model, the ratio

$$
R^{2}=\sum_{k=1}^{m}\left(\hat{y}_{k}-\bar{y}_{k}\right)^{2} / \sum_{k=1}^{m}\left(y_{k}-\bar{y}\right)^{2}
$$

provides a measure of the extent to which the regression model can match the observed data. Specifically, when the variation about the regression model is small (i.e., when $\Sigma_{k}\left(\hat{y}_{k}-y_{k}\right)^{2}$ is a small relative to $\left.\Sigma_{k}\left(\hat{y}_{k}-\bar{y}\right)^{2}\right)$, then the corresponding $R^{2}$ value is close 1 , which indicates that the regression model is accounting for most of the uncertainty in the $y_{k}$. Conversely, an $R^{2}$ value close to zero indicates that the regression model is not very successful in accounting for the uncertainty in the $y_{k}$. Another name for $R^{2}$ is the coefficient of multiple determination.

An important situation occurs when the rows of the matrix $X$ (i.e., the variable values at which the model is evaluated) are selected so that $X^{T} X$ is a diagonal matrix. In this case, the columns of $X$ are said to be orthogonal, and the estimated regression coefficients are given by

$$
\begin{aligned}
\mathbf{b} & =\left(\mathbf{X}^{T} \mathbf{X}\right)^{-1} \mathbf{X}^{T} \mathbf{y} \\
& =\left[\begin{array}{cccc}
d_{0} & 0 & \cdots & 0 \\
0 & d_{1} & 0 \\
\vdots & \vdots & & \vdots \\
0 & 0 & \cdots & d_{n}
\end{array}\right]^{-1}\left[\begin{array}{cccc}
1 & 1 & \cdots & 1 \\
x_{11} & x_{21} & \cdots & x_{m !} \\
\vdots & \vdots & & \vdots \\
x_{l n} & x_{2 n} & \cdots & x_{m n}
\end{array}\right]\left[\begin{array}{c}
y_{1} \\
y_{2} \\
\vdots \\
y_{m}
\end{array}\right]
\end{aligned}
$$


and so each element $b_{j}$ of $\mathbf{b}$ is given by

$$
b_{j}=\sum_{k=1}^{m} x_{k j} y_{k} / d_{j}=\sum_{k=1}^{m} x_{k j} y_{k} / \sum_{k=1}^{m} x_{k j}^{2}
$$

The important point to recognize is that the estimate of the regression coefficient $b_{j}$ for the variable $x_{j}$ depends only on the values for $x_{j}$ in the design matrix $\mathrm{X}$ (i.e., $x_{1 j}, \ldots, x_{m j}$ ). This is true regardless of the number of variables included in the regression. As long as the design is orthogonal, the addition or deletion of variables from the model will not change the regression coefficients. Further, when the design matrix $\mathrm{X}$ is orthogonal, the $R^{2}$ value for the regression can be expressed as

$$
R^{2}=\sum_{k=1}^{m}\left(\hat{y}_{k}-\bar{y}\right)^{2} / \sum_{k=1}^{m}\left(y_{k}-\bar{y}\right)^{2}=R_{1}^{2}+R_{2}^{2}+\cdots+R_{n}^{2},
$$

where $R_{j}^{2}$ is the $R^{2}$ value that results from regressing $y$ on only $x_{j}$ (Eq. (III-74) Helton et al. 1991). Thus, $R_{j}^{2}$ is equal to the contribution of $x_{j}$ to $R^{2}$ when the design matrix $\mathrm{X}$ is orthogonal.

The regression model in Eq. (20) can be algebraically reformulated as

$$
(y-\bar{y}) / \hat{s}=\sum_{j=1}^{n}\left(b_{j} \hat{s}_{j} / \hat{s}\right)\left(x_{j}-\bar{x}_{j}\right) / \hat{s}_{j}
$$

where

$$
\begin{aligned}
& \bar{y}=\sum_{k=1}^{m} y_{k} / m, \quad \hat{s}=\left[\sum_{k=1}^{m}\left(y_{k}-\bar{y}\right)^{2} /(m-1)\right]^{1 / 2}, \\
& \bar{x}_{j}=\sum_{k=1}^{m} x_{k j} / m, \quad \hat{s}_{j}=\left[\sum_{k=1}^{m}\left(x_{k j}-\bar{x}_{j}\right)^{2} /(m-1)\right]^{1 / 2} .
\end{aligned}
$$

The coefficients $b_{j} \hat{s}_{j} / \hat{s}$ appearing in Eq. (32) are called standardized regression coefficients (SRCs). When the $x_{j}$ are independent, the absolute value of the SRCs can be used to provide a measure of variable importance. Specifically, the coefficients provide a measure of importance based on the effect of moving each variable away from its expected value by a fixed fraction of its standard deviation while retaining all other variables at their 
expected values. Calculating SRCs is equivalent to performing the regression analysis with the input and output variables normalized to mean zero and standard deviation one.

An example regression analysis is now given. The output variable (i.e., $y$ ) is pressure $(\mathrm{Pa}$ ) in the repository at $10,000 \mathrm{yr}$ under undisturbed (i.e., E0) conditions (i.e., the pressure values above 10,000 yr in Fig. 5). To keep the example at a convenient size, 3 independent variables (i.e., $x_{j}$ ) will be considered (Table 1): pointer variable for microbial degradation of cellulose (WMICDFLG), halite porosity (HALPOR), and corrosion rate for steel (WGRCOR). The following regression model is obtained using the preceding three variables and the pooled LHS in Eq. (18) (i.e., $n=3$ and $m=300$ ):

$$
y=5.72 \times 10^{6}+2.46 \times 10^{6} \cdot W M I C D F L G+1.55 \times 10^{8} \cdot H A L P O R+1.52 \times 10^{20} \cdot \text { WGRCOR } .
$$

The coefficients in the preceding model show the effect of a one unit change in an input variable (i.e., an $x_{j}$ ) on the output variable (i.e., $y$ ). The sign of a regression coefficient indicates whether $y$ tends to increase (a positive regression coefficient) or tends to decrease (a negative regression coefficient) as the corresponding input variable increases. Thus, $y$ tends to increase as each of WMICDFLG, HALPOR and WGRCOR increases.

It is hard to assess variable importance from the regression coefficients in Eq. (33) because of the effects of units and distribution assumptions. In particular, the regression coefficient for WGRCOR is much larger than the regression coefficients for WMICDFLG and HALPOR, which does not necessarily imply that WGRCOR has greater influence on the uncertainty in y than WMICDFLG or HALPOR. Variable importance is more clearly shown by the following reformation of Eq. (33) with SRCs:

$$
y=0.722 \text { WMICDFLG }+0.468 \text { HALPOR }+0.246 \text { WGRCOR }
$$

The SRCs in Eq. (34) provide a better characterization of variable importance than the unstandardized coefficients in Eq. (33). For perturbations equal to a fixed fraction of their standard deviation, the impact of WMICDFLG is approximately $50 \%$ larger than the impact of $H A L P O R$ (i.e., $(0.722-0.468) / 0.468=0.54$ ) and almost $200 \%$ larger than the impact of WGRCOR (i.e., $(0.722-0.246) / 0.246=1.96)$. Both regression models have an $R^{2}$ value of 0.79 and thus can account for approximately $79 \%$ of the uncertainty in $y$.

\subsection{Correlation and Partial Correlation}

The ideas of correlation and partial correlation are useful concepts that often appear in sampling-based uncertainty/sensitivity studies. For a sequence of observations $\left(x_{i}, y_{i}\right), i=1, \ldots, m$, the (sample) correlation $r_{x y}$ between $x$ and $y$ is defined by 


$$
r_{x y}=\frac{\sum_{k=1}^{m}\left(x_{k}-\bar{x}\right)\left(y_{k}-\bar{y}\right)}{\left[\sum_{k=1}^{m}\left(x_{k}-\bar{x}\right)^{2}\right]^{1 / 2}\left[\sum_{k=1}^{m}\left(y_{k}-\bar{y}\right)^{2}\right]^{1 / 2}}
$$

where $\bar{x}$ and $\bar{y}$ are defined in conjunction with Eq. (32). The correlation coefficient $r_{x y}$ provides a measure of the linear relationship between $x$ and $y$.

The nature of the correlation coefficient $r_{x y}$ is most readily understood by considering the regression

$$
y=b_{0}+b_{1} x
$$

The definition of $r_{x y}$ in Eq. (35) is equivalent to the definition

$$
r_{x y}=\operatorname{sign}\left(b_{1}\right)\left(R^{2}\right)^{1 / 2}
$$

where $\operatorname{sign}\left(b_{1}\right)=1$ if $b_{1} \geq 0, \operatorname{sign}\left(b_{1}\right)=-1$ if $b_{1}<0$, and $R^{2}$ is the coefficient of determination that results from regressing $y$ on $x$. With respect to interpretation, the correlation coefficient $r_{x y}$ provides a measure of the linear relationship between $x$ and $y$, and the regression coefficient $b_{1}$ characterizes the effect that a unit change in $x$ will have on $y$.

When more than one input variable is under consideration, partial correlation coefficients (PCCs) can be used to provide a measure of the linear relationships between the output variable $y$ and the individual input variables. The PCC between $y$ and an individual variable $x_{p}$ is obtained from the use of a sequence of regression models. First, the following two regression models are constructed:

$$
\hat{y}=b_{0}+\sum_{\substack{j=1 \\ j \neq p}}^{n} b_{j} x_{j} \text { and } \hat{x}_{p}=c_{0}+\sum_{\substack{j=1 \\ j \neq p}}^{n} c_{j} x_{j}
$$

Then, the results of the two preceding regressions are used to define the new variables $y-\hat{y}$ and $x_{p}-\hat{x}_{p}$. By definition, the PCC between $y$ and $x_{p}$ is the correlation coefficient between $y-\hat{y}$ and $x_{p}-\hat{x}_{p}$. Thus, the PCC provides a measure of the linear relationship between $y$ and $x_{p}$ with the linear effects of the other variables removed. The preceding provides a rather intuitive development of what a PCC is. A formal development of PCCs and the relationships between PCCs and SRCs is provided by Iman et al. (1985).

The PCC characterizes the strength of the linear relationship between two variables after a correction has been made for the linear effects of the other variables in the analysis, and the SRC characterizes the effect on the output 
variable that results from perturbing an input variable by a fixed fraction of its standard deviation. Thus, PCCs and SRCs provide related, but not identical, measures of variable importance. In particular, the PCC provides a measure of variable importance that tends to exclude the effects of other variables, the assumed distribution for the particular input variable under consideration, and the magnitude of the impact of an input variable on an output variable. In contrast, the value for an SRC is significantly influenced by both the distribution assigned to an input variable and the impact that this variable has on an output variable. However, when the input variables in an analysis are uncorrelated, an ordering of variable importance based on either the absolute value of SRCs or the absolute value of PCCs will yield the same ranking of variable importance, even though the SRCs and PCCs for individual variables may be quite different (Iman et al. 1985).

Many output variables are functions of time or location. A useful way to present sensitivity results for such variables is with plots of PCCs or SRCs. An example of such a presentation for the pressure curves in Fig. 5 is given in Fig. 6, which displays two sets of curves. The one set (Fig. 6a) contains SRCs plotted as a function of time; the other set (Fig. 6b) contains PCCs plotted in a similar manner. For both sets of curves, the dependent variables are pressures at fixed times, and each curve displays the values of SRCs or PCCs relating these pressures to a single input variable as a function of time.

\subsection{Stepwise Regression Analysis}

When many input variables are involved, the direct construction of a regression model containing all input variables as shown in Eq. (20) may not be the best approach for several reasons. First, the large number of variables makes the regression model tedious to examine and unwieldy to display. Second, it is often the case that only a relatively small number of input variables have an impact on the output variable. As a result, there is no reason to include the remaining variables in the regression model. Third, correlated variables result in unstable regression coefficients (i.e., coefficients whose values are sensitive to the specific variables included in the regression model). When this occurs, the regression coefficients in a model containing all the input variables can give a misleading representation of variable importance. As a side point, if several input variables are highly correlated, consideration should be given to either removing all but one of the correlated variables or transforming the variables to correct for (i.e., remove) the correlations between them Fourth, an overfitting of the data can result when variables are arbitrarily forced into the regression model. This phenomenon occurs when the regression model attempts to match the predictions associated with individual sample elements rather than match the trends shown by the sample elements collectively.

Stepwise regression analysis provides an alternative to constructing a regression model containing all the input variables. With this approach, a sequence of regression models is constructed. The first regression model contains the single input variable that has the largest impact on the uncertainty in the output variable (i.e., the input variable that has the largest correlation with the output variable $y$ ). The second regression model contains the two input 
variables that have the largest impact on the output variable: the input variable from the first step plus whichever of the remaining variables has the largest impact on the uncertainty not accounted for by the first variable (i.e., the input variable that has the largest correlation with the uncertainty in $y$ that cannot be accounted for by the first variable). The third regression model contains the three input variables that have the largest impact on the output variable: the two input variables from the second step plus whichever of the remaining variables has the largest impact on the uncertainty not accounted for by the first two variables (i.e., the input variable that has the largest correlation with the uncertainty in $y$ that cannot be accounted for by the first two variables). Additional models in the sequence are defined in the same manner until a point is reached at which further models are unable to meaningfully increase the amount of the uncertainty in the output variable that can be accounted for. Further, at each step of the process, the possibility exists for an already selected variable to be dropped out if it no longer has a significant impact on the amount of uncertainty in the output variable that can be accounted for by the regression model; this only occurs when correlations exist between the input variables.

Several aspects of stepwise regression analysis provide insights on the importance of the individual variables. First, the order in which the variables are selected in the stepwise procedure provides an indication of their importance, with the most important variable being selected first, the next most important variable being selected second, and so on. Second, the $R^{2}$ values (see Eq. (28)) at successive steps of the analysis also provide a measure of variable importance by indicating how much of the uncertainty in the dependent variable can be accounted for by all variables selected through each step. When the input variables are uncorrelated, the differences in the $R^{2}$ values for the regression models constructed at successive steps equals the fraction of the total uncertainty in the output variable that can be accounted for by the individual input variables being added at each step (see Eq. (31)). Third, the absolute values of the SRCs (see Eq. (32)) in the individual regression models provide an indication of variable importance. Further, the sign of an SRC indicates whether the input and output variable tend to increase and decrease together (a positive coefficient) or tend to move in opposite directions (a negative coefficient).

An important situation occurs when the input variables are uncorrelated. In this case, the orderings of variable importance based on order of entry into the regression model, size of the $R^{2}$ values attributable to the individual variables, the absolute values of the SRCs, and the absolute values of the PCCs are the same. In situations where the input variables are believed to be uncorrelated, one of the important applications of the previously discussed restricted pairing technique of Iman and Conover (Sect. 8) is to ensure that the correlations between variables within a Latin hypercube or random sample are indeed close to zero. When variables are correlated, care must be used in the interpretation of the results of a regression analysis since the regression coefficients can change in ways that are basically unrelated to the importance of the individual variables as correlated variables are added to and deleted from the regression model (see Sect. 7.2, Helton et al. 1998e, for an example of the effects of correlated variables on the outcomes of a regression analysis). 
When the stepwise technique is used to construct a regression model, it is necessary to have some criteria to stop the construction process. When there are many independent variables, there is usually no reason to let the construction process continue until all the variables have been used. It is also necessary to have some criteria to determine when a variable is no longer needed and thus can be dropped from the regression model. As indicated earlier, this latter situation only occurs when the input variables are correlated.

The usual criterion for making the preceding decisions is based on whether or not the regression coefficient associated with an input variable appears to be significantly different from zero. Specifically, the $t$-test is used to determine the probability that a regression coefficient as large as or larger than the one constructed in the analysis would be obtained if, in reality, there was no relationship between the input and output variable, and, as a result, the apparent relationship that led to the constructed regression coefficient was due entirely to chance (Sect. 7.5, Neter and Wasserman 1974). The probability of exceeding a regression coefficient due to chance variation is often referred to as an $\alpha$-value. The actual derivation of the $\alpha$-value depends on assumptions involving normality and random variation that are not satisfied in sampling-based sensitivity studies for computer models since there is no variation in the predictions for a fixed set of input. However, the $t$-test and the associated $\alpha$-value still constitute a useful criterion for adding or deleting variables from a regression model in a sensitivity study since they provide a measure of how viable the relationship between the input and output variable would appear to be in a study in which this relationship could possibly have arisen from random variation. Sensitivity studies often use an $\alpha$-value of 0.01 or 0.02 to add a variable to a regression model and a somewhat larger value to drop a variable from the model.

As models involving more variables are developed in a stepwise regression analysis, the possibility exists of overfitting the data. Overfitting occurs when the regression model in essence "chases" the individual observations rather than following an overall pattern in the data. For example, it is possible to obtain a good fit to a set of points by using a polynomial of high degree. However, in doing so, it is possible to overfit the data and produce a spurious model that makes poor predictions.

To protect against overfit, the Predicted Error Sum of Squares (PRESS) criterion can be used to determine the adequacy of a regression model (Allen 1971). For a regression model containing $q$ variables and constructed from $m$ observations, PRESS is computed in the following manner. For $k=1,2, \ldots, m$, the $k$ th observation is deleted from the original set of $m$ observations and then a regression model containing the original $q$ variables is constructed from the remaining $m-1$ observations. With this new regression model, the value $\hat{y}_{q}(k)$ is estimated for the deleted observation $y_{k}$. Then, PRESS is defined from the preceding predictions and the $m$ original observations by

$$
\operatorname{PRESS}_{q}=\sum_{k=1}^{m}\left(y_{k}-\hat{y}_{q}(k)\right)^{2} \text {. }
$$


The regression model having the smallest PRESS value is preferred when choosing between two competing models, as this is an indication of how well the basic pattern of the data has been fitted versus an overfit or an underfit. In particular, PRESS values will decrease in size as additional variables are added to the regression model without an overfitting of the data (i.e., PRESS $_{q}>$ PRESS $_{q+1}$ ), with an increase in the PRESS values (i.e., PRESS $_{q}<P R E S S_{q+1}$ ) indicating an overfitting of the data. In addition to PRESS, there are also a number of other diagnostic tools that can be used to investigate the adequacy of regression models (Cook and Weisberg 1982, Belsley et al. 1980).

It is important to use scatterplots, PRESS values and other procedures to examine the reasonableness of regression models. This is especially true when regression models are used for sensitivity analysis. Such analyses often involve many input variables and large uncertainties in these variables. The appearance of spurious patterns is a possibility that must be checked for.

An example stepwise regression analysis is now presented for repository pressure at 10,000 yr under undisturbed conditions (Fig. 5). The following 31 variables from Table 1 and contained in the three replicated LHSs indicated in Eq. (14) are used as input to calculations performed with BRAGFLO in the 1996 WIPP PA: ANHBCEXP, ANHBCVGP, ANRBRSAT, ANHCOMP, ANHPRM, ANRGSSAT, BHPRM, BPCOMP, BPINTPRS, BPPRM, BPVOL, HALCOMP, HALPOR, HALPRM, SALPRES, SHBCEXP, SHPRMASP, SHPRMCLY, SHPRMCON, SHPRMDRZ, SHPRMHAL, SHRBRSAT, SHRGSSAT, WASTWICK, WFBETCEL, WGRCOR, WGRMICH, WGRMICI, WMICDFLG, WRBRNSAT and WRGSSAT. Variables within the pairs (ANHCOMP, $A N H P R M)$ and (HALCOMP, HALPOR) have rank correlations of -0.99 (Table 1, Fig. 2), which creates instabilities in regression results (Sect. 7.2, Helton et al. 1998e). Therefore, to avoid the distracting effects that result from the presence of highly correlated variables, ANHCOMP and HALCOMP will not be included as independent variables in the following example. Thus, the data available for analysis are of the form

$$
\left[x_{k 1}, x_{k 2}, \ldots, x_{k, 29,} y_{k}\right], k=1,2, \ldots, m=300
$$

where $y_{k}$ is the value for pressure obtained with the $k$ th sample element (i.e., $y=W A S_{-} P R E S$ at $10,000 \mathrm{yr}$ in Fig. 5), the $x_{k j}, j=1,2, \ldots, 29$, correspond to the variables indicated above with ANHCOMP and HALCOMP omitted, and a value of $m=300$ results from pooling the three replicated LHSs (i.e., R1, R2, R3).

The variables $B H P R M, B P C O M P, B P I N T P R S, B P P R M$ and $B P V O L$ do not effect repository pressure under undisturbed conditions and thus could be omitted from consideration. However, they are left in this example to increase the number of variables that must be considered in the stepwise process. Also, leaving such variables in an analysis can be beneficial from an analysis verification perspective. In particular, an error in the implementation of the analysis is indicated if such unimportant variables show up as having identifiable effects. Similarly, errors are indicated when variables are identified as having effects that are inconsistent with their known usage within the analysis. 
The first step selects the input variable $x_{j}$ that has the largest impact on the output variable $y$. Specifically, this is defined to be the variable that has the largest correlation, in absolute value, with $y$ (see Eqs. (35) and (37)). Thus, it is necessary to calculate the correlations between $y$ and each of the 29 input variables under consideration. For illustration, Table 3 shows the $7 \times 7$ correlation matrix for $y$ and the six input variables ultimately selected in the stepwise regression, although the full correlation matrix would actually be $(29+1) \times(29+1)$. Each element in the correlation matrix is the correlation between the variables in the corresponding row and column. As examination of the correlation matrix in Table 3 shows, the variable $W M I C D F L G$ has the highest correlation with waste pressure, which is denoted by WAS PRES. Thus, the first step in the analysis selects the variable WMICDFLG. A regression model relating $y$ to WMICDFLG is then developed as shown in Eq. (25) with $n=1$ and $m=300$. The resultant regression model is

$$
\hat{\mathrm{y}}=8.94 \times 10^{6}+2.43 \times 10^{6} \cdot W M I C D F L G
$$

which has an $R^{2}$ value of 0.508 , an $\alpha$-value of 0.0000 , an SRC of 0.712 and a PRESS value of $1.20 \times 10^{15}$. This model is summarized in Table 4.

The second step selects the input variable $x_{j}$ that has the largest impact on the uncertainty in the output variable $y$ that cannot be accounted by WMICDFLG, the variable selected in the first step. This selection is made by defining a new variable

$$
\tilde{y}=y-\hat{y}=y-\left(8.94 \times 10^{6}+2.43 \times 10^{6} \cdot W M I C D F L G\right),
$$

where $\hat{y}$ is defined in Eq. (41), and then calculating the correlations between $\tilde{y}$ and the remaining variables. The variable with the largest correlation, in absolute value, with $\tilde{y}$ is selected as the second variable for inclusion in the model. In this example, the selected variable is $H A L P O R$. The regression model at this step will thus involve the two variables WMICDFLG and HALPOR and is constructed as shown in Eq. (6.10.11) with $n=2$ and $m=300$. The resultant regression model is

$$
\hat{y}=6.89 \times 10^{6}+2.49 \times 10^{6} \cdot \text { WMICDFLG }+1.57 \times 10^{8} \cdot \text { HALPOR }
$$

This model is summarized in Table 4 .

The third step selects the input variable $x_{j}$ that has the largest impact on the uncertainty in the output variable $y$ that cannot be accounted for by WMICDFLG and HALPOR, the two variables from the second step. This selection is made by defining a new variable

$$
\tilde{y}=y-\hat{y}=y-\left(6.89 \times 10^{6}+2.49 \times 10^{6} \cdot W M I C D F L G+1.57 \times 10^{8} \cdot \text { HALPOR }\right)
$$


where $\hat{y}$ is defined in Eq. (43). The variable with the largest correlation, in absolute value, with $\tilde{y}$ is selected as the third variable for inclusion in the model. In this example, the selected variable is WGRCOR. The regression model for this step will thus involve the three variables WMICDFLG, HALPOR and WGRCOR. The resultant regression model is summarized in Table 4.

As shown in Table 4, the stepwise procedure then continues in the same manner through a total of six steps, until no more variables can be found with an $\alpha$-value less than 0.02 . At this point, the stepwise procedure stops.

At each step, the stepwise procedure also checks to see if any variable selected at a prior step now has an $\alpha-$ value that exceeds a specified level, which is 0.05 in this analysis. If such a situation occurs, the variable will be dropped from the analysis, with the possibility that it may be reselected at a later step as other variables are added and deleted from the model. This type of behavior only occurs when there are correlations between the input variables. As shown in the example correlation matrix in Table 3, the restricted pairing technique has been successful in keeping the correlations between the input variables close to zero. Thus, no variables meet the criterion to be dropped from the regression model once they have been selected at a prior step.

Another result of this lack of correlation is that the regression coefficients do not change significantly as additional variables are added to the regression model. As examination of Table 4 shows, the regression coefficients for a specific variable are essentially the same in all regression models containing that variable. Further, as indicated in Eq. (31), the $R^{2}$ values obtained for successive models can be subtracted to obtain the contribution to the uncertainty in $y$ due to the newly added variable. Thus, for example, WMICDFLG accounts for approximately $51 \%$ of the uncertainty in $y$ (i.e., $R^{2}=0.508$ ), while WMICDFLG and HALPOR together account for approximately $73 \%$ of the uncertainty (i.e., $R^{2}=0.732$ ). As a result, $H A L P O R$ by itself accounts for approximately $73 \%-51 \%=22 \%$ of the uncertainty in $y$. Similar results hold for the other variables selected in the analysis.

Table 4 also reports the PRESS values for the regression models obtained at the individual steps in the analysis. A decreasing sequence of PRESS values indicates that the regression models are not overfitting the data on which they are based. An increase in the PRESS values suggests that a model is overfitting the data, and thus that the stepwise procedure should probably be stopped at the preceding step. As shown by the decreasing PRESS values in Table 4 , the regression models in this analysis are probably not overfitting the data from which they were constructed.

Typically, a certain amount of discretion is involved in selecting the exact point at which to stop a stepwise regression analysis. Certainly, $\alpha$-values and the behavior of PRESS values provide two criteria to consider in selecting a stopping point. Other criteria include the changes in the $R^{2}$ values that take place as additional variables are added to the regression models and whether or not spurious variables are starting to enter the regression models. When only very small changes in $R^{2}$ values are taking place (e.g., $\leq 0.01$ ), there is often little reason to continue the 
stepwise process. When $\alpha$-values approach or exceed 0.01 and a large number of input variables are being considered, it is fairly common to start getting spurious variables in the regression. Such variables appear to have a small effect on the output variable which, in fact, is due to chance variation. In such situations, a natural stopping point may be just before spurious variables start being selected. Another possibility is to delete spurious variables from the regression model.

When the input variables are uncorrelated, a display of the results of a stepwise regression analysis as shown in Table 4 contains a large amount of redundant information. A more compact display can be obtained by listing the variables in the order that they entered in the regression model, the $R^{2}$ values obtained with the entry of successive variables into the regression model, and the SRCs for the variables contained in the final model. Table 5 shows what this summary looks like for the stepwise regression analysis presented in Table 4.

\subsection{The Rank Transformation}

Regression and correlation analyses often perform poorly when the relationships between the input and output variables are nonlinear. This is not surprising since such analyses are based on developing linear relationships between variables. The problems associated with poor linear fits to nonlinear data can often be avoided by use of the rank transformation (Iman and Conover 1979). The rank transformation is a simple concept: data are replaced with their corresponding ranks and then the usual regression and correlation procedures are performed on these ranks. Specifically, the smallest value of each variable is assigned the rank 1, the next largest value is assigned the rank 2 , and so on up to the largest value, which is assigned the rank $m$, where $m$ denotes the number of observations. The analysis is then performed with these ranks being used as the values for the input and output variables.

Example regression analyses with raw (i.e., untransformed) and rank-transformed data follow. The output variable (i.e., $y$ ) is cumulative brine flow over 10,000 yr under undisturbed (i.e., E0) conditions from the anhydrite marker beds (MBs) to the disturbed rock zone (DRZ, see Fig. ??, Vaughn et al. 1998) that surrounds the repository (i.e., the cumulative flow values above $10,000 \mathrm{yr}$ in Fig. 7). The results of the stepwise regression analyses with raw and rank-transformed data can be summarized in the compact form illustrated in Table 5 and show that the analysis with rank-transformed data is outperforming the analysis with raw data (Table 6). In particular, the analysis with rank-transformed data can account for approximately $87 \%$ of the uncertainty in $y$ (i.e., $R^{2}=0.869$ ), while the analysis with raw data can account for only $50 \%$ of the uncertainty in $y$ (i.e., $R^{2}=0.496$ ). Further, the regression with rank-transformed data indicates a stronger effect for WMICDFLG (i.e., $R^{2}=0.425$ ) than is indicated by the regression with raw data (i.e., $R^{2}=0.423-0.320=0.103$ ).

The analysis with rank-transformed data is more effective than the analysis with raw data because the rank transformation tends to linearize the relationships between the independent variables (i.e., the $x_{j}$ s) and the dependent variable (i.e., y). In particular, both WMICDFLG and $A N H P R M$ show a better defined linear relationship with $y$ after 
the rank transformation (Fig. 8). The rank transformation improves the analysis when nonlinear but monotonic relationships exist between the independent variables and the dependent variable. When more complex relationships exist, the rank transformation may do little to improve the quality of an analysis. In such cases, more sophisticated procedures may be required. For example, the chi square test can be used to test for deviations from randomness in scatterplots (Kleijnen and Helton 1998, Wagner 1995); other techniques also exist (Hamby 1994, Saltelli and Marivoet 1990).

As is the case for stepwise regression analyses, analyses wth SRCs and PCCs of the type presented in Fig. 6 can often be improved with the use of rank-transformed data. When the rank transform is used, the resultant plots will contain standardized rank regression coefficients (SRRCs) and partial rank correlation coefficients (PRCCs). As an example, the results of analyzing the cumulative brine inflows in Fig. 7 with both raw and rank-transformed data are presented in Fig. 9, with each plot frame showing the five variables with the largest, in absolute value, SRCs, PCCs, SRRCs and PRCCs as appropriate. As in the comparisons of stepwise regression analyses with raw and ranktransformed data (Table 6), the analyses with rank-transformed data in Fig. 9 produce outcomes that indicate stronger effects for individual variables than is the case for the analyses with raw data. 
Table 2. Example Rank Correlations in Replicate 1

\begin{tabular}{|c|c|c|c|c|c|c|c|c|}
\hline WGRCOR & 1.0000 & & & & & & & \\
\hline WMICDFLG & 0.0198 & 1.0000 & & & & & & \\
\hline HALCOMP & 0.0011 & 0.0235 & 1.0000 & & & & & \\
\hline HALPRM & -0.0068 & -0.0212 & -0.9879 & 1.0000 & & & & \\
\hline$A N H C O M P$ & 0.0080 & 0.0336 & -0.0123 & -0.0025 & 1.0000 & & & \\
\hline$A N H P R M$ & 0.0049 & -0.0183 & 0.0037 & 0.0113 & -0.9827 & 1.0000 & & \\
\hline ВРCOMP & 0.0242 & 0.1071 & -0.0121 & 0.0057 & -0.0184 & 0.0078 & 1.0000 & \\
\hline \multirow[t]{2}{*}{$B P P R M$} & -0.0514 & -0.0342 & 0.0035 & 0.0097 & 0.0283 & -0.0202 & -0.7401 & 1.0000 \\
\hline & WGRCOR & WMICDFLG & HALCOMP & $H A L P R M$ & ANHCOMP & $A N H P R M$ & $B P C O M P$ & $B P P R M$ \\
\hline
\end{tabular}

Table 3. Correlation Matrix for Variables Selected in Stepwise Regression Analysis for Pressure in the Repository at 10,000 yr Under Undisturbed Conditions (i.e., $y=$ WAS_PRES at 10,000 yr in Fig. 5)

\begin{tabular}{lccccccc}
\hline WMICDFLG & 1.0000 & & & & & & \\
HALPOR & -0.0348 & 1.0000 & & & & & \\
WGRCOR & 0.0272 & 0.0216 & 1.0000 & & & & \\
ANHPRM & 0.0008 & -0.0039 & 0.0130 & 1.0000 & & & \\
SHRGSSAT & -0.0026 & 0.0395 & -0.0171 & -0.0042 & 1.0000 & & \\
SALPRES & 0.0560 & -0.0072 & 0.0010 & -0.0117 & 0.0061 & 1.0000 & \\
WAS_PRES & 0.7124 & 0.4483 & 0.2762 & 0.1303 & 0.0820 & 0.0993 & 1.0000 \\
& WMICDFLG & HALPOR & WGRCOR & ANHPRM & SHRGSSAT & SALPRES & WAS_PRES \\
\hline
\end{tabular}


Table 4. Results of Stepwise Regression Analysis for Pressure in the Repository at 10,000 yr Under Undisturbed Conditions (i.e., $y=$ WAS_PRES at 10,000 yr in Fig. 5)

\begin{tabular}{|c|c|c|c|c|c|}
\hline Step ${ }^{2}$ & Variables $^{\mathrm{b}}$ & $\mathrm{SRC}^{\mathrm{c}}$ & $\alpha$-Values ${ }^{d}$ & $R^{2}$ Values ${ }^{e}$ & PRESS \\
\hline 1 & $W M I C D F L G$ & 0.712 & 0.0000 & 0.508 & $1.20 \times 10^{15}$ \\
\hline \multirow[t]{2}{*}{2} & WMICDFLG & 0.729 & 0.0000 & \multirow[t]{2}{*}{0.732} & \multirow[t]{2}{*}{$6.59 \times 10^{14}$} \\
\hline & $H A L P O R$ & 0.474 & 0.0000 & & \\
\hline \multirow[t]{3}{*}{3} & $W M I C D F L G$ & 0.722 & 0.0000 & \multirow[t]{3}{*}{0.792} & \multirow[t]{3}{*}{$5.14 \times 10^{14}$} \\
\hline & HALPOR & 0.468 & 0.0000 & & \\
\hline & WGRCOR & 0.246 & 0.0000 & & \\
\hline \multirow[t]{4}{*}{4} & WMICDFLG & 0.722 & 0.0000 & \multirow[t]{4}{*}{0.809} & \multirow[t]{4}{*}{$4.79 \times 10^{14}$} \\
\hline & HALPOR & 0.469 & 0.0000 & & \\
\hline & $W G R C O R$ & 0.245 & 0.0000 & & \\
\hline & $A N H P R M$ & 0.128 & 0.0000 & & \\
\hline \multirow[t]{5}{*}{5} & $W M I C D F L G$ & 0.722 & 0.0000 & \multirow[t]{5}{*}{0.814} & \multirow[t]{5}{*}{$4.70 \times 10^{14}$} \\
\hline & HALPOR & 0.466 & 0.0000 & & \\
\hline & WGRCOR & 0.246 & 0.0000 & & \\
\hline & $A N H P R M$ & 0.129 & 0.0000 & & \\
\hline & SHRGSSAT & 0.070 & 0.0056 & & \\
\hline \multirow[t]{6}{*}{6} & $W M I C D F L G$ & 0.718 & 0.0000 & \multirow[t]{6}{*}{0.818} & \multirow[t]{6}{*}{$4.63 \times 10^{14}$} \\
\hline & HALPOR & 0.466 & 0.0000 & & \\
\hline & $W G R C O R$ & 0.246 & 0.0000 & & \\
\hline & ANHPRM & 0.129 & 0.0000 & & \\
\hline & SHRGSSAT & 0.070 & 0.0055 & & \\
\hline & SALPRES & 0.063 & 0.0012 & & \\
\hline \multicolumn{6}{|c|}{ Steps in the analysis } \\
\hline \multicolumn{6}{|c|}{ b Variables selected at each step with $A N H C O M P$ and $H A L C O M P$ excluded from entry into the regression model } \\
\hline \multicolumn{6}{|c|}{ c Standardized regression coefficients (SRCs) for variables in the regression model at each step } \\
\hline \multicolumn{6}{|c|}{$\begin{array}{l}\text { d } \alpha \text {-values for variables in the regression model at each step } \\
\text { - } R^{2} \text { value for the regression model at each step }\end{array}$} \\
\hline$R^{2}$ value for & ission model at each & & & & \\
\hline
\end{tabular}


Table 5. Compact Summary of Stepwise Regression Analyses for Pressure in the Repository at 10,000 yr Under Undisturbed Conditions (i.e., $y=$ WAS_PRES at 10,000 yr in Fig. 5).

\begin{tabular}{|c|l|l|l|}
\hline Step $^{a}$ & \multicolumn{1}{|c|}{ Variable $^{b}$} & SRC $^{c}$ & $R^{2 \mathrm{~d}}$ \\
\hline 1 & WMICDFLG & 0.718 & 0.508 \\
2 & HALPOR & 0.466 & 0.732 \\
3 & WGRCOR & 0.246 & 0.792 \\
4 & ANHPRM & 0.129 & 0.809 \\
5 & SHRGSSAT & 0.070 & 0.814 \\
6 & SALPRES & 0.063 & 0.818 \\
\hline
\end{tabular}

${ }^{3}$ Steps in stepwise analysis.

${ }^{b}$ Variables listed in the order of selection in regression analysis with ANHCOMP and HALCOMP excluded from entry into regression model.

' $S$ tandardized regression coefficients (SRCs) for variables in final regression model.

${ }^{d}$ Cumulative $R^{2}$ value with entry of each variabie into regression model.

Table 6. Comparison of Stepwise Regression Analyses with Raw and Rank-Transformed Data for Cumulative Brine Flow over 10,000 yr under Undisturbed Conditions from the Anhydrite Marker Beds to the Disturbed Rock Zone that Surrounds the Repository (i.e., $y=B R A A L / C$ at $10,000 \mathrm{yr}$ in Fig. 7).

\begin{tabular}{|c|l|l|l|l|r|r|}
\cline { 2 - 7 } \multicolumn{1}{c|}{} & \multicolumn{3}{c|}{ Raw Data } & \multicolumn{3}{c|}{ Rank-Transformed Data } \\
\hline Step $^{\mathrm{a}}$ & Variable & SRC & $R^{2 \mathrm{~d}}$ & Variable & SRRC $^{\mathrm{b}}$ & $R^{2 \mathrm{~d}}$ \\
\hline 1 & ANHPRM & 0.562 & 0.320 & WMICDFLG & -0.656 & 0.425 \\
2 & WMICDFLG & -0.309 & 0.423 & ANHPRM & 0.593 & 0.766 \\
3 & WGRCOR & -0.164 & 0.449 & HALPOR & -0.155 & 0.802 \\
4 & WASTWICK & -0.145 & 0.471 & WGRCOR & -0.152 & 0.824 \\
5 & ANHBCEXP & -0.120 & 0.486 & HALPRM & 0.143 & 0.845 \\
6 & HALPOR & -0.101 & 0.496 & SALPRES & 0.120 & 0.860 \\
7 & & & & WASTWICK & -0.010 & 0.869 \\
\hline
\end{tabular}

a Steps in stepwise regression analysis.

b Variables listed in order of selection in regression analysis with $A N H C O M P$ and $H A L C O M P$ excluded from entry into regression model.

- Standardized regression coefficient (SRCs) in final regression model.

d Cumulative $R^{2}$ value with entry of each variable into regression model.

- Standardized rank regression coefficients (SRRCs) in final regression model. 